\title{
Installing Extra Bicarbonate Transporters in the Cyanobacterium Synechocystis sp. PCC6803 Enhances Biomass Production
}

Nina A. Kamennaya ${ }^{1, *}$, Se Eun Ahn, Hanwool Park ${ }^{2}$, Roy Bartal, Kenji A. Sasaki ${ }^{3}$, Hoi-Ying

Holman, Christer Jansson ${ }^{4, *}$

Lawrence Berkeley National Laboratory, 1 Cyclotron Road, Berkeley, CA 94720, USA (N.A.K., S.E.A., H.P., K.A.S., H.Y.H., C.J.);

Romberg Tiburon Center for Environmental Studies, San Francisco State University, 3150

Paradise Drive, Tiburon, CA 94920 (R.B.).

Present addresses:

${ }^{1}$ School of Life Sciences, University of Warwick, Gibbet Hill Road, Coventry, CV4 7AL, UK

${ }^{2}$ National Marine Bioenergy Research Center \& Department of Biological Engineering, Inha

University, 100 Inharo, Nam-gu Incheon, 402-751, Korea

${ }^{3}$ Intel Corporation, 3065 Bowers Avenue, Santa Clara, CA 95054, USA

${ }^{4}$ Pacific Northwest National Laboratory, P.O. Box 999, K8-93, Richland, WA 99352

*Corresponding authors:

Christer Jansson, cgjansson@lbl.gov

Nina A. Kamennaya, n.kamennaya@warwick.ac.uk 


\section{ABSTRACT}

2 As a means to improve carbon uptake in the cyanobacterium Synechocystis sp. strain PCC6803, 3 we engineered strains to contain additional inducible copies of the endogenous bicarbonate 4 transporter $\mathrm{BicA}$, an essential component of the $\mathrm{CO}_{2}$-concentrating mechanism in cyanobacteria. 5 When cultured under atmospheric $\mathrm{CO}_{2}$ pressure, the strain expressing extra BicA transporters 6 (BicA $^{+}$strain) grew almost twice as fast and accumulated almost twice as much biomass as the 7 control strain. When enriched with $0.5 \%$ or $5 \% \mathrm{CO}_{2}$, the $\mathrm{BicA}^{+}$strain grew slower than the 8 control but still showed a superior biomass production. Introducing a point mutation in the large 9 C-terminal cytosolic domain of the inserted BicA, at a site implicated in allosteric regulation of 10 transport activity, resulted in a strain $\left(\mathrm{BicA}_{(\mathrm{T} 485 \mathrm{G})}^{+}\right.$strain) that exhibited pronounced cell 11 aggregation and failed to grow at $5 \% \mathrm{CO}_{2}$. However, the bicarbonate uptake capacity of the 12 induced $\mathrm{BicA}_{(\mathrm{T} 485 \mathrm{G})}^{+}$was twice higher than for the wild-type strain. Metabolic analyses, 13 including phenotyping by synchrotron-radiation Fourier transform Infrared spectromicroscopy, 14 scanning electron microscopy, and lectin staining, suggest that the excess assimilated carbon in $15 \mathrm{BicA}^{+}$and $\mathrm{BicA}_{(}^{+}{ }_{(485 \mathrm{G})}$ cells was directed into production of saccharide-rich exopolymeric 16 substances. We propose that the increased capacity for $\mathrm{CO}_{2}$ uptake in the $\mathrm{BicA}^{+}$strain can be 17 capitalized on by re-directing carbon flux from exopolymeric substances to other end products 18 such as fuels or high-value chemicals. 
Keywords

20 CCM, cyanobacteria, bicarbonate transporter, engineering 
22 Some photoautotrophs including cyanobacteria have inducible mechanisms that allow the cells to raise the concentration of $\mathrm{CO}_{2}$ at the carboxylation site of ribulose-1,5-bisphosphate carboxylase/oxygenase (rubisco; EC 4.1.1.1.39) up to 1000-fold over that in the surrounding medium (Kaplan et al., 1980; Giordano et al., 2005). This capacity has evolved in response to decrease in the atmospheric $\mathrm{CO}_{2}$ partial pressure $\left(p \mathrm{CO}_{2}\right)$ and increase in the $\mathrm{OO}_{2}$ since emergence of cyanobacteria. Under the present-day ambient conditions, the slow turnover rate of rubisco and its ability to utilize not only $\mathrm{CO}_{2}$ but also $\mathrm{O}_{2}$ as substrate impair the carboxylation efficiency cyanobacteria and algae, the situation is exacerbated by the low availability of $\mathrm{CO}_{2}$ in water, where it has a diffusion rate four orders of magnitude slower than in air and where bicarbonate $\left(\mathrm{HCO}_{3}{ }^{-}\right)$is the predominant dissolved inorganic carbon (DIC) species at circumneutral or slightly alkaline $\mathrm{pH}$ (Price, 2011). Details of the $\mathrm{CO}_{2}$-concentrating mechanism (CCM) in cyanobacteria differ between species but the salient features, depicted in Fig. 1, include a series of $\mathrm{HCO}_{3}{ }^{-}$and $\mathrm{CO}_{2}$ transporters and the carboxysome, a protein-enclosed organelle-like micro-compartment that houses (most of) the rubisco protein and also contains different isoforms of the enzyme carbonic anhydrase (CA; EC 4.2.1.1) (Cannon et al., 2010; Yeates et al., 2010; Price, 2011; Rae et al., 2013). DIC enters the cells mainly via $\mathrm{HCO}_{3}{ }^{-} / \mathrm{Na}^{+}$symports but also through diffusion of $\mathrm{CO}_{2}$. To limit seepage of $\mathrm{CO}_{2}$ from the cell, CA-harboring NADPH dehydrogenase (NDH) complexes in the thylakoid and plasma membranes protonate incoming $\mathrm{CO}_{2}$ to $\mathrm{HCO}_{3}{ }^{-}$according to the dissociation reaction:

$\mathrm{CO}_{2}+\mathrm{H}_{2} \mathrm{O} \leftrightarrows \mathrm{H}^{+}+\mathrm{HCO}_{3}^{-}$(Reaction 1 )

Under conditions of low DIC availability, e.g. in alkaline environments, when carbonate $\left(\mathrm{CO}_{3}{ }^{2-}\right)$ species dominate over $\mathrm{CO}_{2}$ and $\mathrm{HCO}_{3}{ }^{-}$, the $\mathrm{CCM}$ is activated, supporting effective flux of $\mathrm{HCO}_{3}{ }^{-}$into the cytosol (Fig. 1). The cytosolic $\mathrm{HCO}_{3}{ }^{-}$subsequently enters the carboxysome where it is converted by $\mathrm{CA}$ to $\mathrm{CO}_{2}$ for the rubisco carboxylation (Reaction 1, Fig. 1). At nonlimiting DIC concentrations, e.g. in a neutral $\mathrm{pH}$ environment or under $p \mathrm{CO}_{2}>0.4 \%$, the $\mathrm{CCM}$ is down-regulated to a basic, constitutive level, characterized by mainly $\mathrm{CO}_{2}$ uptake (Price and Howitt, 2010; Ramanan et al., 2012). The cyanobacterium Synechocystis sp. strain PCC6803 (further S. 6803) harbors three different $\mathrm{HCO}_{3}{ }^{-}$transporters (Fig. 1). BicA (encoded by locus sll0834), a constitutive high-flux low-affinity $\mathrm{Na}^{+} / \mathrm{HCO}_{3}{ }^{-}$symport, and SbtA (encoded by locus 
52 slr1512), an inducible low-flux high-affinity $\mathrm{Na}^{+} / \mathrm{HCO}_{3}{ }^{-}$symport, are single-component

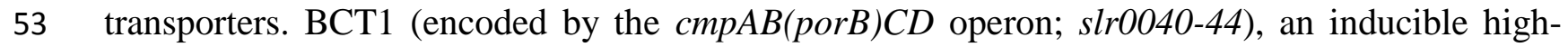
54 affinity uniport, is a multi-component ATP-dependent transporter. The inducible SbtA and BCT1 55 transporters are strictly regulated at the transcriptional level by the CcmR transcription factor, 56 which senses intracellular levels of $\alpha$-ketoglutarate and NADP ${ }^{+}$(Daley et al., 2012).

57

58

59

60

61

62

63

64

65

66

67

68

69

70

71

72

73

74

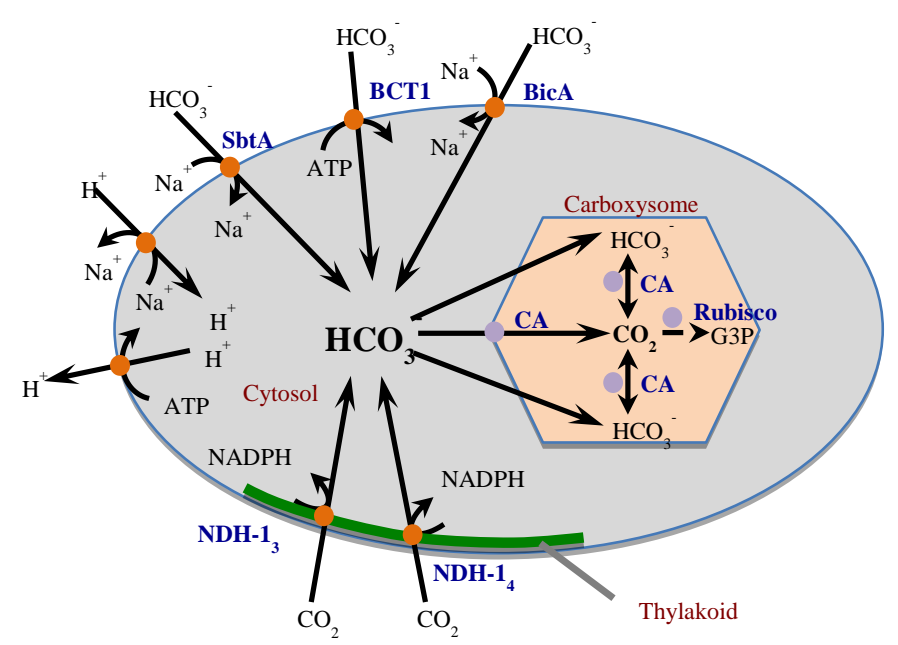

Figure 1. The CCM in Synechocystis sp. PCC6803. The BicA, SbtA and BCT1 $\mathrm{HCO}_{3}{ }^{-}$

transporters, and the redox-powered NDH-1 $1_{3}$ and NDH- $1_{4} \mathrm{CO}_{2}$ uptake systems are depicted. At low DIC levels, SbtA, BCT1 and $\mathrm{NDH}-1_{3}$ are activated, allowing for efficient transport of $\mathrm{HCO}_{3}{ }^{-}$ into the cytosol. Import of $\mathrm{HCO}_{3}{ }^{-}$into the carboxysome and its subsequent conversion to $\mathrm{CO}_{2}$ by different carbonic anhydrase (CA) activities increases the local concentration of $\mathrm{CO}_{2}$ around Rubisco. $\mathrm{Na}^{+} / \mathrm{H}^{+}$antiports and $\mathrm{H}^{+}$-ATPases are likely to be engaged to maintain intracellular $\mathrm{Na}^{+}$ and $\mathrm{pH}$ homeostasis.

Utilization of cyanobacteria for photosynthetic conversion of $\mathrm{CO}_{2}$ to fuels and chemicals through introduction of heterologous (e.g. monoterpene biosynthesis), or enhancement of endogenous (e.g. alkane biosynthesis) pathways results in increased carbon (C) and electron sink demand (the "pull” end of photosynthetic metabolism), especially when targeting high-yield production. Since photosynthetic source strength (the "push" end of photosynthesis, i.e., primary photochemistry and Calvin-Benson cycle), is often controlled by sink demand (Paul et al., 2001; Iwaki et al., 2006; McCormick et al., 2006; Jansson et al., 2010; Ducat et al., 2012; Oliver et al., 2013), mostly via sugar signaling (Jansson, 2005; Rolland et al., 2006), an increase in sink strength may in itself be enough to enhance overall photosynthesis. However, to make full use of the potential 
75 for photosynthetic production in cyanobacteria it will be necessary to maximize both the pull and

76 push end of photosynthesis, and restructure the metabolic link between them.

77 Increasing photosynthetic source strength in cyanobacteria entails enhancement of light and 78 inorganic $\mathrm{C}\left(\mathrm{C}_{\mathrm{i}}\right)$ uptake and light utilization. In the present study we aimed at enhancing $\mathrm{C}_{\mathrm{i}}$ 79 uptake in $S .6803$ by installing additional copies of the single-component and high-flux $\mathrm{HCO}_{3}$ transporter BicA. To be able to control expression of the introduced transporter, we used the nir operon promoter nirP that is induced in absence of ammonium in the medium (Suzuki et al.,

82 1993) and that has been shown to drive expression of transgenes in Synechococcus sp. PCC7942

83 (Price et al., 2004; Long et al., 2010) and S. 6803 (Qi et al., 2005). The S. 6803 strain endowed with extra $\mathrm{BicA}$ transporters $\left(\mathrm{BicA}^{+}\right.$strain) was investigated for growth properties and 85 photosynthetic and metabolic performance.

86 Although the BicA activity is not regulated at the transcriptional level (Wang et al., 2004), it is 87 likely controlled allosterically, possibly through reversible phosphorylation in the cytosolic C88 terminal Sulfate Transporter Anti-Sigma (STAS) domain (Aravind and Koonin, 2000; Shelden et al., 2010), with suppression imposed by cell exposure to high $\mathrm{C}_{\mathrm{i}}$ concentrations (Karagouni et al., 1990; Bloye et al., 1992). In an attempt to retain high $\mathrm{HCO}_{3}{ }^{-}$influx in $\mathrm{C}_{\mathrm{i}}$-replete $S$. 6803, we generated a second strain containing a threonine-to-glycine substitution in the phosphorylatable and highly conserved T485 (S. 6803 numbering; T489 in Synechococcus sp. PCC7002 (Shelden et al., 2010)) in the installed BicA transporter. The properties of this strain $\left(S .6803 \mathrm{BicA}^{+}{ }_{(\mathrm{T} 485 \mathrm{G})}\right.$ strain) were compared with those of $S .6803 \mathrm{BicA}^{+}$and the wild type (WT).

MATERIALS AND METHODS

97 The glucose-intolerant Synechocystis sp. strain PCC6803, obtained from The Pasteur Culture 98 Collection (www. pasteur.fr) was referred to as the WT strain and served as the control. Plasmids and gene constructs Plasmid $p$ KRP13 (Reece and Phillips, 1995) was a kind gift from Gregory Phillips, Iowa State 101 University. DNA constructs were designed using the MacVector software (www.macvector.com) 102 and synthesized by GenScript (www.genscript.com).

103 We used the $p s b A I$ gene as an integrative platform in the $S .6803$ genome. The $p s b A I$ gene 104 encodes the photosystem II reaction center protein D1 isoform shown to be beneficial only under 
105

106

107

108

109

110

111

112

113

114

115

116

117

118

119

120

121

122

123

124

125

126

127

128

129

130

131

132

133

134

135

marginal growth conditions, e.g., in microanaerobic environment (Sicora et al., 2009) or with strong light and high ammonium concentrations (Dai et al., 2014). Under growth conditions used in this study, we considered the $p s b A l$ gene as dispensable (Jansson et al., 1987) and used it as a neutral integrative platform. A 226 base pairs (bp) fragment upstream of nirA containing the nirP in Synechococcus sp. strain PCC7942 was designed to terminate with a multiple cloning site and was flanked with the psbAI fragments. Insertion of this construct into the pUC56-simple (Hu et al., 2013) generated the $p$ FUEL70 plasmid (Supplementary Fig. S1). Using KpnI restriction sites, the streptomycin/spectinomycin $(\mathrm{Str} / \mathrm{Spc})$-resistance cassette was transferred from $p \mathrm{KRP} 13$ to $p$ FUEL70 to create $p$ FUEL70b (Supplementary Fig. S1).

The bicA gene (Supplementary Fig. S2) was amplified by PCR from the genomic DNA of $S$. 6803 by using the primer pair bicNdeI-F (5' - GGGGATATTGACATATGCAAATAACTAAC AAAATTCATTTTAGG - 3') and bicSpeI-R (5' - CGCCGGGGCACTAGTCAGTATGTGG 3'). Underlined bases indicate NdeI and SpeI restriction sites that were incorporated into the primer sequences. PCR amplification, performed with Phusion high-fidelity DNA polymerase (NEB, www.neb.com) at annealing temperature of $56.5^{\circ} \mathrm{C}$, yielded a 1723 -bp product. The amplicon was digested with NdeI and SpeI (NEB), gel-purified (Qiagen MinElute Gel Extraction kit, www.qiagen.com), and ligated into the NdeI- and SpeI-digested $p$ FUEL70b (NEB Quick Ligation $^{\mathrm{TM}}$ kit), resulting in the $p$ FUEL70b::bicA.

To disable allosteric inhibition of the BicA transport activity, we used site-directed mutagenesis to alter regulatory phosphorylation switch previously mapped to a conserved loop of the Cterminal STAS domain of BicA (Aravind and Koonin, 2000). In Bacillus subtilis, a serine-toalanine substitution of the phosphorylatable serine (S58) located in conserved loop of the STASdomain antisigma-factor antagonist SpoIIAA was detrimental to regulatory activity of the protein (Diederich et al., 1994). Based on multiple alignment of the conserved loop in STAS domains (Aravind and Koonin, 2000), threonine at the position 485 (T485) in BicA of S. 6803 (T489 in Synechococcus sp. PCC7002 (Shelden et al., 2010)) was homologous to S58 and therefore could potentially be involved in reversible phosphorylation and impose regulation upon the transporter. To substitute T485 with non-phosphorylatable glycine (Supplementary Fig. S2), we used an internal primer, bicA-Gly-F (5' - CCATTTGGGAGTAggCGCTTCCCTGG - 3') and its reverse complement sequence bicA-Gly-R. Underlined bases indicate the glycine-coding nucleotide triplet, with lower cases indicating the introduced mismatches. Two separate PCRs with the 
bicNdeI-F/bicA-Gly-R and bicA-Gly-F/bicSpeI-R primers $\left(\mathrm{Ta} 72^{\circ} \mathrm{C}\right)$ yielded two bicA fragments (1480 and $270 \mathrm{bp}$ ) bearing the threonine-to-glycine substitution. Fusion PCR with the overlapping amplicons as a template resulted in amplification of the full-length bicA sequence bearing the substituted nucleotides (bicA(T485G)). The bicA(T485G) sequence was ligated into $p$ FUEL70b as above, resulting in the formation of $p$ FUEL70b::bicA(T485G).

\section{Cyanobacterial strains and growth conditions}

Transformation of $S .6803$ with the $p$ FUEL70b::bicA and $p$ FUEL70b::bicA(T485G) constructs and propagation of the transformants on selective media were performed as described (Eaton-

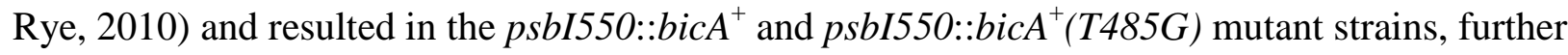
referred to as $\mathrm{BicA}^{+}$and $\mathrm{BicA}^{+}{ }_{(\mathrm{T} 485 \mathrm{G}) \text {. }}$

For cell cultivations, we used liquid BG11 medium (Stanier et al., 1971), supplemented with 8.8 $\mathrm{mM}$ ammonium (BG11- $\mathrm{NH}_{4}{ }^{+}$) and buffered with $10 \mathrm{mM} \mathrm{N}$-Tris-(hydroxymethyl)methyl-2aminoethanesulfonic acid (TES)- $\mathrm{NaOH}(\mathrm{pH}$ 8.2) to prevent medium acidification. Liquid cultures were placed in Innova 44 shaking incubator at $30^{\circ} \mathrm{C}$ with $160 \mathrm{rpm}$ agitation under continuous illumination of $\sim 50 \mu \mathrm{mol}$ photons $\mathrm{m}^{-2} \mathrm{~s}^{-1}$. Mutant cultures were supplemented with $50 \mu \mathrm{g} \mathrm{mL}^{-1}$ streptomycin. For investigation of growth properties, cells were cultivated in $30 \mathrm{~mL}$ tubes, purged with air or air-balance gas mixtures containing $0.5 \%$ or $5 \% \mathrm{CO}_{2}(\mathrm{v} / \mathrm{v})$ at a rate of 1 $\mathrm{L}$ gas $\min ^{-1} \mathrm{~L}^{-1}$, or with no aeration (ambient). The nitrate-based medium (BG11- $\mathrm{NO}_{3}{ }^{-}$containing $8.8 \mathrm{mM} \mathrm{NaNO}_{3}$ ) was used to induce the BicA constructs during the cultures growth. For strong induction of the BicA construct, the cells were transferred to BG11 $1_{0}$ medium containing no $\mathrm{N}$ source ( $\mathrm{N}$ source was substituted with $49.6 \mathrm{~g} \mathrm{~L}^{-1} \mathrm{NaCl}$ ), purged with air, and starved for $\mathrm{N}$ shortly prior to the analyses.

\section{Pigments determination}

For quantitative determination of cell phycobilliprotein content, $2 \mathrm{~mL}$ of a mid-log culture were harvested by centrifugation. Cells were re-suspended in $1 \mathrm{~mL}$ of phosphate buffer saline (10 mM, pH7.2) and lysed with glass beads $(0.1 \mathrm{~mm})$ using a FastPrep ${ }^{\circledR}-24$ beadbeater (MP Biomedicals, www.mpbio.com) with nine breaking cycles of $30 \mathrm{sec}$ alternated with chilling the sample on ice. Subsequently, the sample was centrifuged, the supernatant containing extracted pigments was collected, and absorbance of the supernatant was measured at 562, 615, and 652 nm using a Beckman DU 640 Spectrophotometer (Beckman Coulter Inc., 
166

167

168

169

170

171

172

173

174

175

176

177

178

179

180

181

182

183

184

185

186

187

188

189

190

191

192

193

194

195

www.beckmancoulter.com). Phycobilliprotein concentrations were calculated after Bennett and Bogorad (1973).

Chl was extracted from cell pellets $\left(1 \mathrm{~mL} ; \mathrm{OD}_{750}\right.$ of $\left.\sim 1.5\right)$ with $100 \%$ methanol, and the concentration was estimated spectrophotometrically (Lichtentahler, 1987).

Microscopy

Cell sizes were averaged from at least 10 cells visualized at the transmitted light bright field mode with 1000 x magnification using an up-right Axioskop 50 (Carl Zeiss Microscopy, www.zeiss.com/microscopy/). Images were captured with the MacroFire_C camera (Optronics, http://optronics.com/) and the PictureFrame (TM) App1.2.3 software.

For cell counts, cells were serially diluted, collected on a $0.2-\mu \mathrm{m}$ Anodisc $®$ membrane filter (Whatman), and counted at $1000 \mathrm{x}$ magnification using Axioskop 50 (Carl Zeiss Microscopy). At least 8 fields were counted for at least 3 dilutions.

For lectin stains, control or N-starved cells were pelleted by gentle centrifugation at $2000 \mathrm{x} g$ for $1 \mathrm{~min}$, re-suspended in $10 \mathrm{mM}$ 4-(2-hydroxyethyl)-1-piperazineethanesulfonic acid (HEPES) buffer $\mathrm{pH} 7.5$, and added to a final concentration of $5 \mu \mathrm{g} \mathrm{mL}^{-1}$ with fluorescein isothiocyanateconjugated lectins (Vector Laboratories, Burlingame, CA) concanavalin A (ConA), wheat germ agglutinin (WGA), Ricinus communis agglutinin I (RCA I), and/or Ulex Europaeus agglutinin I (UEA I), specifically binding mannose, $\mathrm{N}$-acetylglucosamine, galactose and $\mathrm{N}$ acetylgalactosamine, or fucose respectively. The cells were gently agitated for one hour in dark at room temperature, washed twice with HEPES buffer, mounted on Polysine adhesion slides (ThermoFisher Scientific, www.thermofisher.com), and imaged with Zen 2010 software and 710 Laser Scanning Confocal Microscope (Carl Zeiss Microscopy) using $488 \mathrm{~nm}$ (lectin conjugate fluorescence) and $594 \mathrm{~nm}$ (cyanobacterial autofluorescence) lines.

For SEM, control or N-starved cells incubated with $100 \mathrm{mM} \mathrm{HCO}_{3}{ }^{-}$for $1 \mathrm{~h}$ were fixed at $+4^{\circ} \mathrm{C}$ overnight with glutaraldehyde (4\% v/v final concentration), mounted on a silicon wafer, washed twice with DDW, and let dry under air. The cells were dehydrated by graded series of ethanol washes and sputtered with 136A gold film (Polaron SC7640, Quorum Technologies Ltd., www.quorumtech.com). The imaging was performed with an Ultra-55 Field Emission Scanning Electron Microscope (Carl Zeiss Microscopy), operated in a secondary electron mode at $5 \mathrm{kV}$.

Oxygen evolution 
Cells were cultivated in BG11- $\mathrm{NH}_{4}{ }^{+}$or $\mathrm{BG} 11-\mathrm{NO}_{3}{ }^{-}$infused with air and harvested at a mid-log phase $\left(\mathrm{OD}_{750} 0.4\right.$ - 0.7). For strong induction of the introduced BicA constructs, cultures from BG11- $\mathrm{NO}_{3}{ }^{-}$were transferred to $\mathrm{BG} 11_{0}$ medium, infused with air, and incubated under standard cultivation conditions for 3 hours prior to the analysis. For determination of the oxygen evolution, not induced (BG11- $\left.\mathrm{NH}_{4}{ }^{+}\right)$, mildly induced $\left(\mathrm{BG} 11-\mathrm{NO}_{3}{ }^{-}\right)$, and strongly induced $\left(\mathrm{BG} 11_{0}\right)$ cells were harvested by centrifugation at $5000 \mathrm{x} \mathrm{g}$ for $5 \mathrm{~min}$ at room temperature, washed, and resuspended to a final $\mathrm{Chl} a$ concentration of $7.5-10 \mu \mathrm{g} \mathrm{mL}{ }^{-1}$ in low- $\mathrm{C}_{\mathrm{i}} \mathrm{BG} 11_{0}$ buffered with $10 \mathrm{mM}$ BisTrisPropane buffer to $\mathrm{pH}$ 9.3. The cells were supplemented with 15 $\mathrm{mM} \mathrm{NaCl}$ and allowed to reach the $\mathrm{CO}_{2}$ compensation point at a photon flux density of 100-150 $\mu \mathrm{mol}$ photons $\mathrm{m}^{-2} \mathrm{~h}^{-1}$ (Salon et al., 1996) shortly prior to the analysis. Oxygen evolution was measured using a standard Clark-type electrode (Hansatech Oxygraph with a DW-1 chamber), under a constant light of $400 \mu \mathrm{mol}$ photons $\mathrm{m}^{-2} \mathrm{~h}^{-1}$. As the BicA transporter was shown to be slow to respond to added $\mathrm{HCO}_{3}{ }^{-}$(Price et al., 2004), the maximal value of $\mathrm{O}_{2}$ evolution per minute measured during the first 5 min was recorded.

\section{$\zeta$-potential measurement}

Cells were transferred to BG1 $1_{0}$ supplemented with $10 \mathrm{mM} \mathrm{NaHCO}_{3}$ or $100 \mathrm{mM} \mathrm{NaHCO}_{3}$ and incubated under standard cultivation conditions for $3 \mathrm{~h}$. Then the cells were gently pelleted by centrifugation, washed once with TE buffer (10 mM Tris- $\mathrm{HCl}, \mathrm{pH} 8.0 ; 1 \mathrm{mM}$ EDTA) to remove cations, resuspended in sterile ice-cold distilled water, split to two tubes, and kept on ice. $\mathrm{CaCl}_{2}$ was added to one tube to a final concentration of $10 \mathrm{mM}$. The $\mathrm{pH}$ in both tubes was adjusted to 8.0 using FE20-FiveEasy ${ }^{\mathrm{TM}}$ pH meter (Mettler Toledo International Inc., Columbus, OH). Electrophoretic mobility of the cells was measured at $+25^{\circ} \mathrm{C}$ using Zetasizer Nano ZS (Malvern Instruments Ltd, UK) and automatically converted to $\zeta$-potential using the Smoluchowski’s equation.

\section{DIC determination}

Cells were starved for $\mathrm{N}$ as described above, resuspended to a final $\mathrm{OD}_{750}$ of $\sim 0.6$ with $\mathrm{BG} 11_{0}$ buffered with $10 \mathrm{mM}$ BTP to $\mathrm{pH} 9.3$, and supplemented with $15 \mathrm{mM}$ of $\mathrm{NaCl}$ and $10 \mathrm{mM}$ $\mathrm{NaHCO}_{3}$. The 300-mL cultures were incubated in static hermetically sealed 0.5 -L polystyrene tissue culture flasks (Corning, www.corning.com) at $30{ }^{\circ} \mathrm{C}$ with $275 \mu \mathrm{mol}$ photons $\mathrm{m}^{-2} \mathrm{~s}^{-1}$. Samples for DIC determination were withdrawn at time zero and after 40, 80, and 150 min of 
226 incubation. DIC was determined according to Friederich et al. (2002) except that the $\mathrm{N}_{2}$ carrier

227 gas was replaced with pure $\mathrm{O}_{2}$. The DIC values were standardized against a Dickson standard 228 (batch \#131, Marine Physical Laboratory, Scripps Institution of Oceanography, La Jolla, CA).

\section{Quantification of the extracellular carbohydrate}

230 Cells were starved for $\mathrm{N}$ as described above, supplemented with $\mathrm{HCO}_{3}{ }^{-}$to $10 \mathrm{mM}$ or $100 \mathrm{mM}$

231 final concentrations, and incubated under standard conditions for $1 \mathrm{~h}$. Following vigorous vortex, 232 cultures were centrifuged at $8000 \mathrm{x}$ g for $5 \mathrm{~min}$ to pellet the cells. The collected supernatant was 233 filtered through a $0.45-\mu \mathrm{m}$ polyethersulfone disk membrane (VWR) to remove the residual cells 234 and carbohydrates were precipitated with 2 vol. of ice-cold pure ethanol at $-20{ }^{\circ} \mathrm{C}$ overnight. The 235 carbohydrate pellet, obtained by centrifugation at $16,000 \mathrm{xg}$ for $30 \mathrm{~min}$ at $+4^{\circ} \mathrm{C}$, was washed 236 with ice-cold ethanol (95\% v/v), dried under air flow, and resuspended in $100 \mu \mathrm{LDW}$.

237 Carbohydrate concentrations were determined according to Masuko (2005) with SpectraMax ${ }^{\circledR}$ 238 340PC384 Absorbance Microplate Reader (Molecular Devises).

239

240

241

242

243

244

245

246

247

248

249

250

251

252

253

254

\section{Infrared Spectromicroscopy}

Synchrotron radiation-based Fourier transform infrared (SR-FTIR) metabolic fingerprinting of the WT S. 6803 and mutant strains $\mathrm{BicA}^{+}$and $\mathrm{BicA}_{(\mathrm{T} 485 \mathrm{G})}^{+}$was performed at the infrared beamline of the Advanced Light Source at the Lawrence Berkeley National Laboratory (http://infrared.als.lbl.gov). Ten $\mu 1$ of cells in saline solution $(0.9 \% \mathrm{w} / \mathrm{v} \mathrm{NaCl})$ was placed on $\mathrm{Si}$ wafer chips and all the free-flowing solution was removed. All SR-FTIR absorption spectra were collected in transmission mode at a spectral resolution of $4 \mathrm{~cm}^{-1}$ with 16 co-added scans and a peak position accuracy of $1 / 100 \mathrm{~cm}^{-1}$, which were followed by baseline removal, vector normalization, and multivariate principal component-linear discriminant analysis (PC-LDA) using MathLab (7.0) as described in $\mathrm{Hu}$ et al. (2013). Spectral interpretation was guided by literature (Tipson, 1968; Cabaniss and McVey, 1995; Brandenburg and Seydel, 1996; Kačuráková et al., 2000; Naumann, 2000).

\section{RESULTS}

Construction of the S. $6803 \mathrm{BiCA}^{+}$and $\mathrm{BiCA}^{+}{ }_{\text {T485G }}$ strains

Constructs containing the $\operatorname{bicA}$ and $\operatorname{bicA}(T 485 G)$ genes were introduced into $S$. 6803 for integration into the psbAl (slr1181) locus (Jansson et al., 1987), yielding the $\mathrm{BicA}^{+}$and 
$\mathrm{BicA}^{+}{ }_{(\mathrm{T} 485 \mathrm{G})}$ strains. To allow for controlled expression of the introduced genes, they were placed under control of the nir promoter (nirP) (Qi et al., 2005), which can be activated by shifting the nitrogen $(\mathrm{N})$ source from ammonia to nitrate, or by N starvation (Suzuki et al., 1993; Qi et al., 2005). Plasmid maps and sequences are shown in Supplemental Fig. S1 and S2. SDS-PAGE of N-starved cells is shown in Supplemental Fig. S3.

\section{Growth characteristics}

Liquid stocks of WT and $\mathrm{BicA}^{+}$had similar Chlorophyll (Chl) $a$ contents when Chl $a$ concentrations were normalized to culture turbidity $\left(\mathrm{OD}_{750}\right)$. However, $\mathrm{BicA}^{+}$cells were twice the volume of WT cells and contained $\sim 15 \%$ more Chl $a$ per individual cell (Supplementary Table SI). Interestingly, $\mathrm{BicA}^{+}{ }_{\mathrm{T} 485 \mathrm{G}}$ cells were the smallest but contained the highest concentration of Chl $a$ (Supplementary Table SI).

For growth experiments, WT and engineered strains were cultivated in $\mathrm{BG} 11-\mathrm{NO}_{3}{ }^{-}$to induce BicA constructs in the $\mathrm{BicA}^{+}$and $\mathrm{BicA}_{(\mathrm{T} 485 \mathrm{G})}^{+}$strains.
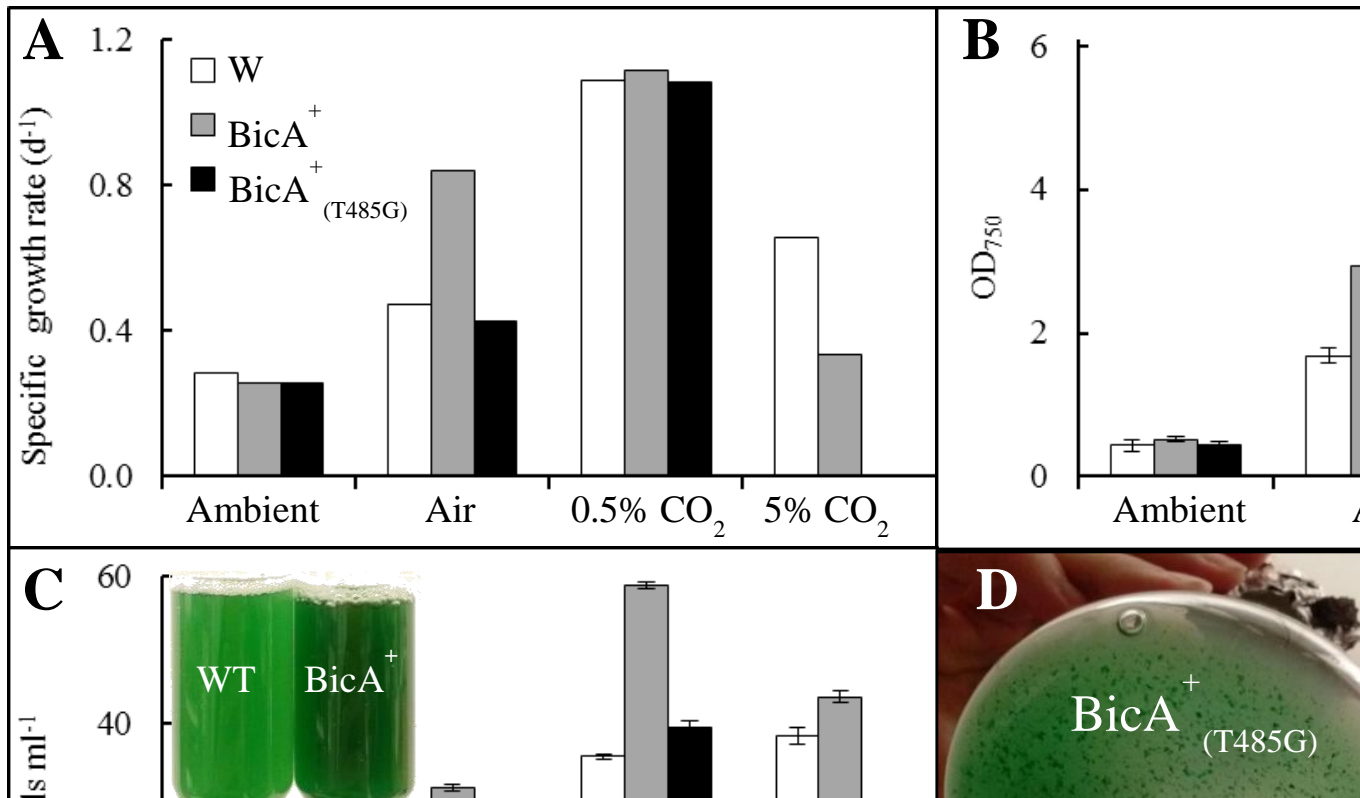

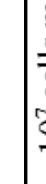

$$
\begin{aligned}
& \text { 总 }
\end{aligned}
$$

Figure 2. Analysis of growth performance of $S .6803 \mathrm{WT} \mathrm{BicA}^{+}$, and $\mathrm{BicA}^{+}{ }_{(\mathrm{T} 485 \mathrm{G})}$ cultures. A, Specific growth rate, measured as doubling time in exponential phase; B, Maximal turbidity 
271 measured as optical density; and C, Maximal cell concentrations reached at a stationary phase of

272 the cultures without gas aeration (ambient), or infused with air or air-balanced gas mixtures

273 containing $0.5 \%$ or $5 \% \mathrm{CO}_{2}$. Data used for bar graphs are presented in Supplemental Table SII.

274 The insert in $\mathrm{C}$ exemplifies $0.5 \% \mathrm{CO}_{2}$ cultures at stationary phase. D, Formation of aggregates

275 was a common feature of $\mathrm{Bic}^{+}{ }_{(\mathrm{T} 485 \mathrm{G})}$ cells.

276

277 To assess the effect of extra $\mathrm{HCO}_{3}{ }^{-}$acquisition capacity on cellular growth properties, DIC was 278 provided either 1) with air infusion $\left(0.038 \% \mathrm{CO}_{2}\right)$ to yield medium DIC availability; 2) sparged 279 with $0.5 \% \mathrm{CO}_{2}$ to supply DIC just above the $\mathrm{CCM}$ activation threshold; 3) sparged with $5 \% \mathrm{CO}_{2}$ to maintain high DIC availability. Alternatively, cells were grown in static non-aerated cultures to represent severe DIC limitation. In liquid cultures infused with air, the $\mathrm{BicA}^{+}$strain grew almost twice as fast as the WT and reached $\sim 30 \%$ higher biomass, measured as turbidity at 750 $\mathrm{nm}$ or as cell concentration (Fig. 2 and S4, Table SII). In cultures infused with $0.5 \% \mathrm{CO}_{2}$, the growth rate for the WT strain was twice as fast as in air cultures, while that for the BicA $^{+}$strain increased by $25 \%$ only (Fig. 2A, Table SII). Under these conditions, both strains had similar growth rates, however, the accumulation of biomass in the $\mathrm{BicA}^{+}$culture was $70-100 \%$ higher than in the WT culture (Fig. 2; insert in 2C). When the $\mathrm{CO}_{2}$ fraction in the infused gas mixture was raised to $5 \%$, the growth rate decreased for both strains, more so for $\mathrm{BicA}^{+}$than for the WT 289 (Fig. 2A). Despite its slower growth rate, the period of active growth for $\mathrm{BicA}^{+}$was longer than for the WT, resulting in higher production of cellular biomass (Fig. 2 and S4). Severely DIClimited cultures (ambient, Fig. 2 and S4) grew slowly and generated low biomass, with no significant difference between $\mathrm{WT}$ and $\mathrm{BicA}^{+}$strains. The $\mathrm{BicA}_{(\mathrm{T} 485 \mathrm{G})}^{+}$strain exhibited approximately the same growth rates as the WT, except when infused with $5 \% \mathrm{CO}_{2}$ when it failed to grow (Fig. 2 and S4). Compared to the WT, maximal turbidity of BicA $^{+}{ }_{(\mathrm{T} 485 \mathrm{G})}$ cultures was similar in the absence of gas infusion and when infused with air, and slightly higher when infused with $0.5 \% \mathrm{CO}_{2}$ (Fig. $2 \mathrm{~B}$ and Table SII). We noted that $\mathrm{BicA}^{+}{ }_{(\mathrm{T} 485 \mathrm{G})}$ cells, despite vigorous mixing of the culture before sampling, often formed clumps, which might compound calculations of growth rates (Fig. 2D). 
To assess differences in $\mathrm{HCO}_{3}{ }^{-}$uptake capacity between the $S .6803 \mathrm{WT}$, $\mathrm{BicA}^{+}$, and $\mathrm{BicA}^{+}{ }_{(\mathrm{T} 485 \mathrm{G})}$ strains, we measured their photosynthetic oxygen $\left(\mathrm{O}_{2}\right)$ evolution. Control WT, $\mathrm{BicA}^{+}$, and $\mathrm{BicA}^{+}{ }_{(\mathrm{T} 485 \mathrm{G})}$ cultures were cultivated in $\mathrm{BG} 11-\mathrm{NH}_{4}{ }^{+}$medium to a mid-log phase and, hence, the engineered strains were not induced for the BicA constructs. For induction, the cultures were cultivated in $\mathrm{BG} 11-\mathrm{NO}_{3}{ }^{-}$. Shortly prior to the analyses, the cells were transferred to BG11 0 without DIC supplement and buffered to $\mathrm{pH}$ 9.3. At this $\mathrm{pH}, \mathrm{HCO}_{3}{ }^{-}$is the obligate source for $\mathrm{C}$ fixation since only $0.018 \%$ of the total $\mathrm{C}_{\mathrm{i}}$ is found in a form of $\mathrm{CO}_{2}$ under chemical equilibrium. Therefore we assumed that $\mathrm{HCO}_{3}{ }^{-}$uptake was at or close to a 1:1 ratio to photosynthetic $\mathrm{O}_{2}$ evolution (Price et al., 2004) up to the saturation of the carbon fixation. The solution was supplemented with $15 \mathrm{mM} \mathrm{NaCl}$ to support $\mathrm{Na}^{+}$-dependent activity of the BicA transporter (Price et al., 2004). Increasing amounts of $\mathrm{NaHCO}_{3}$ were added to cell aliquots and the maximal $\mathrm{O}_{2}$ evolution at $400 \mu \mathrm{mol}$ photons $\mathrm{m}^{-2} \mathrm{~s}^{-1}$ was determined for the following $5 \mathrm{~min}$ and plotted as a function of $\mathrm{HCO}_{3}{ }^{-}$concentration. WT, $\mathrm{BicA}^{+}$, and $\mathrm{BicA}^{+}{ }_{(\mathrm{T} 485 \mathrm{G})}$ cultures showed similar responses to increasing DIC concentrations, with the highest rate of $300-350 \mu \mathrm{mol} \mathrm{O} 2 \mathrm{mg}$ Chl $a^{-1} \mathrm{~h}^{-1}$ reached at DIC concentrations $\geq 125 \mu \mathrm{M}$ (Fig. 3). Moderate increase in $\mathrm{O}_{2}$ evolution

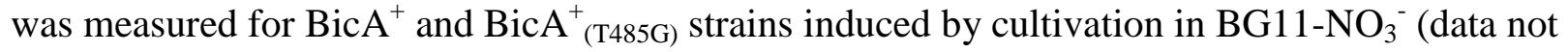
shown). In an attempt to increase the induction magnitude, we starved the S. $6803 \mathrm{WT}$, $\mathrm{BicA}^{+}$, and $\mathrm{BicA}^{+}{ }_{(\mathrm{T} 485 \mathrm{G})}$ cells for $\mathrm{N}$ for $3 \mathrm{~h}$ prior to $\mathrm{O}_{2}$ evolution measurements. This short starvation yielded the highest capacity for $\mathrm{HCO}_{3}{ }^{-}$uptake, presumably by strongly inducing the BicA constructs in $\mathrm{BicA}^{+}$and $\mathrm{BicA}^{+}{ }_{(\mathrm{T} 485 \mathrm{G})}$, while having no profound effect on the WT. Supplemented with $5 \mathrm{mM} \mathrm{HCO}_{3}{ }^{-}, \mathrm{BicA}^{+}{ }_{(\mathrm{T} 485 \mathrm{G})}$ showed an $\mathrm{O}_{2}$ evolution rate twice that of the WT, but rates remained similar at DIC concentration $<100 \mu \mathrm{M}$ (Fig. 3). In the following experiments, we used short $\mathrm{N}$ starvation prior to the analyses as a means to obtain strong induction for the Bic A constructs. 

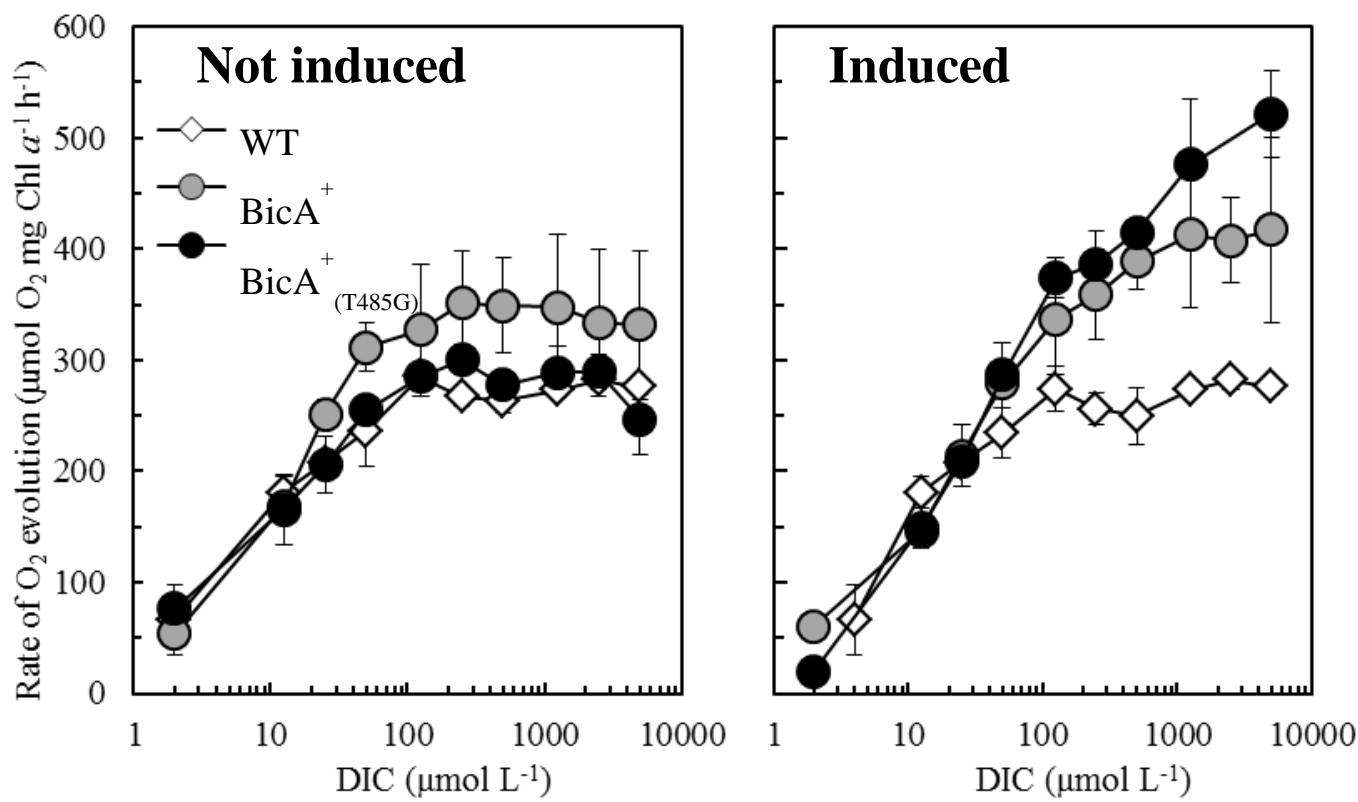

324

325

326

327

Figure 3. Indirect assessment of $\mathrm{HCO}_{3}{ }^{-}$consumption rate. The rate of photosynthetic $\mathrm{O}_{2}$ evolution, measured as a function of DIC for cultures of $S .6803 \mathrm{WT} \mathrm{BicA}^{+}$, or $\mathrm{BicA}^{+}{ }_{(\mathrm{T} 485 \mathrm{G})}$ strains non-induced (left) or strongly induced for the BicA constructs (right).

\section{Rate of bicarbonate uptake}

To directly assess the maximal rate of $\mathrm{HCO}_{3}{ }^{-}$uptake, we monitored the concentration of DIC in the medium of S. $6803 \mathrm{WT}, \mathrm{BicA}^{+}$, and $\mathrm{BicA}_{(\mathrm{T} 485 \mathrm{G})}^{+}$cultures over time. Cells were collected from mid-log cultures and strongly induced for the BicA constructs, as described above. The

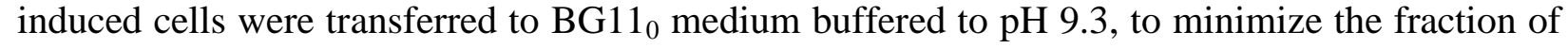
$\mathrm{CO}_{2}$ that could potentially be utilized by cyanobacteria and to obviate the impact of photosynthetic $\mathrm{CO}_{2}$ uptake on DIC concentrations. DIC was determined for the media samples collected at time zero and 40, 80, and $150 \mathrm{~min}$ after introduction of the cells into the medium. The results showed an uptake rate of $1.33 \pm 0.12$ and $2.25 \pm 0.44 \mathrm{mg} \mathrm{DIC} \mathrm{h}^{-1}\left(10^{7} \text { cells }\right)^{-1}$ for the $\mathrm{BicA}^{+}$and $\mathrm{BicA}_{(\mathrm{T} 485 \mathrm{G})}^{+}$strains, respectively, as compared to $1.17 \pm 0.34 \mathrm{mg} \mathrm{DIC} \mathrm{h}^{-1}\left(10^{7}\right.$ cells $^{-1}$ for the WT (Fig. 4). 


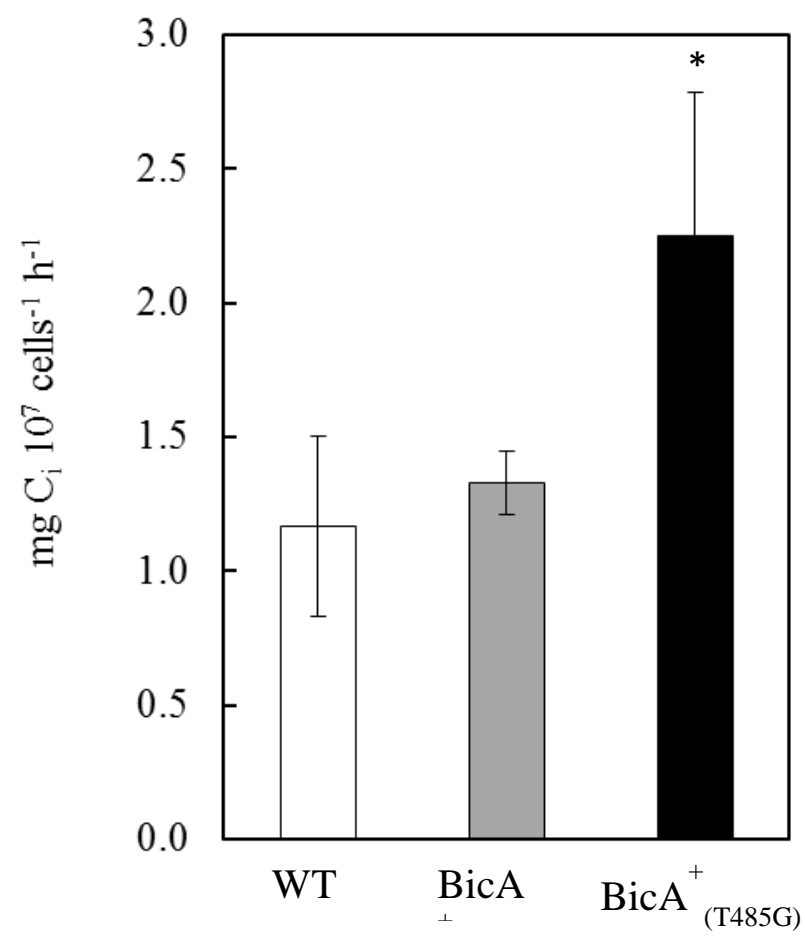

Figure 4. Direct measurement of $\mathrm{HCO}_{3}{ }^{-}$consumption rate. The rate of $\mathrm{HCO}_{3}{ }^{-}$consumption was measured for S. $6803 \mathrm{WT}$, and $\mathrm{BicA}^{+}$or $\mathrm{BicA}_{(\mathrm{T} 485 \mathrm{G})}^{+}$strains strongly induced for the BicA constructs. *Denotes statistically significant difference as compared to the WT control (t-test, $\mathrm{p}<0.05)$.

\section{Structural analysis}

Scanning electron micrographs of the WT control, $\mathrm{BicA}^{+}$, and $\mathrm{BicA}^{+}{ }_{(\mathrm{T} 485 \mathrm{G})}$ cells, with no induction for the BicA constructs, revealed only minor morphological differences between the strains (Fig. 5). Short N starvation had no profound effect on the WT cells, even when they were supplemented with $100 \mathrm{mM} \mathrm{HCO}_{3}{ }^{-}$(Fig. 5). In contrast, $\mathrm{BicA}^{+}$and particularly $\mathrm{BicA}^{+}{ }_{(\mathrm{T} 485 \mathrm{G})}$ cultures strongly induced for the BicA constructs accumulated noticeable quantities of extracellular material after a short incubation with $100 \mathrm{mM} \mathrm{HCO}_{3}{ }^{-} \cdot \mathrm{BicA}^{+}{ }_{(\mathrm{T} 485 \mathrm{G})}$ cells appeared mainly in aggregates, cemented by the exudate. A zoom-in micrograph of the $\mathrm{BicA}^{+}{ }_{(\mathrm{T} 485 \mathrm{G})}$ cells showed "pancake-like structures" of the exuding material spreading over the cell surface (Fig. 5).

To investigate the nature of the organic material exuded by the $\mathrm{BicA}^{+}$and $\mathrm{BicA}_{(\mathrm{T} 485 \mathrm{G})}^{+}$strains, we probed cells with lectins specific to carbohydrates in exopolymeric substances (EPS) often 
355 produced by cyanobacteria (Sengbusch and Müller, 1983; Neu and Lawrence, 1997). BicA ${ }^{+}$and

356 particularly $\mathrm{BicA}_{(\mathrm{T} 485 \mathrm{G})}^{+}$cells induced for the BicA constructs were associated with strong

357 signals from fluorescent lectins (Fig. S5) indicative of the presence of glucose, mannose,

358 galactose, $\mathrm{N}$-acetylglucosamine, $\mathrm{N}$-acetylgalactosamine, and fucose on surface of the cells. Only

359 occasional staining was observed for WT cells, or for the $\mathrm{BicA}^{+}$and $\mathrm{BicA}^{+}{ }_{(\mathrm{T} 485 \mathrm{G})}$ strains not

360 induced for the BicA construct (Fig. S5). The $\zeta$-potential values for strongly induced $\mathrm{BicA}^{+}$and

$361 \mathrm{BicA}^{+}{ }_{(\mathrm{T} 485 \mathrm{G})}$ cells suspended in double distilled water (DDW) were $20 \%$ and $30 \%$ more negative

$362(-64.1 \pm 1.51$ and $-69.3 \pm 1.29$, respectively) than the value for the WT $(-52.8 \pm 1.7 \mathrm{mV})$. In

363 presence of $\mathrm{Ca}^{2+}$, which is readily absorbed by negatively charged residues of acidic

364 polysaccharides, the negative $\zeta$-potential for all cell types was partially neutralized, converging

365 at around $-14.4 \pm 1.1$ (Fig. 6). The magnitude of neutralization is indicative of the relative amount

366 of acidic extracellular polysaccharides for each type of the cells.

\section{Not induced}

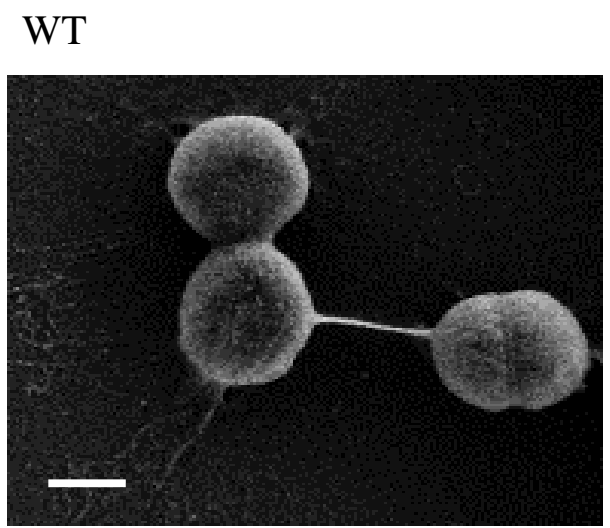

Induced

WT

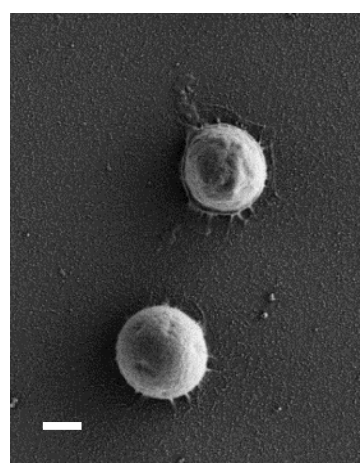

$\mathrm{BicA}^{+}$

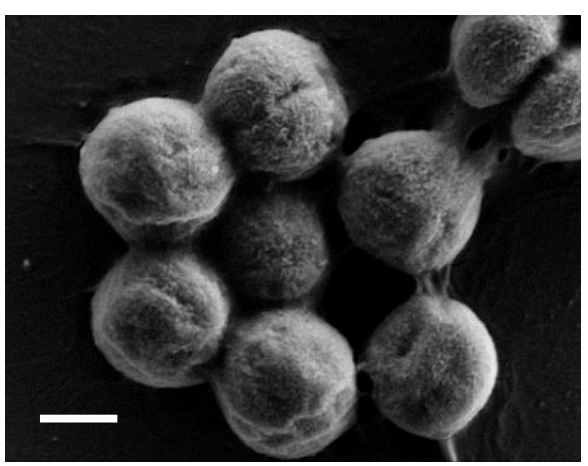

$\mathrm{BicA}_{(\mathrm{T} 485 \mathrm{G})}^{+}$

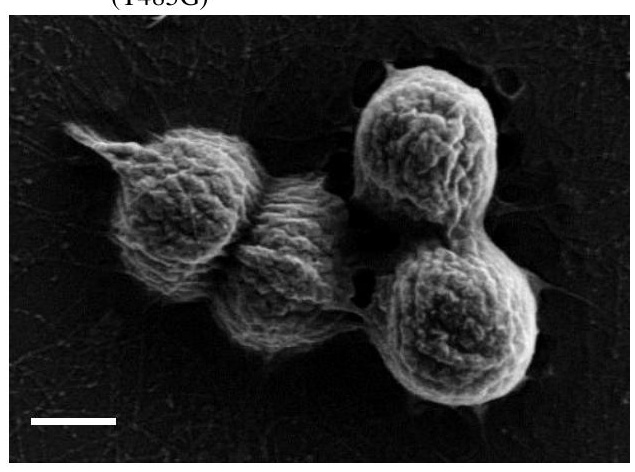

$\mathrm{BicA}^{+}$

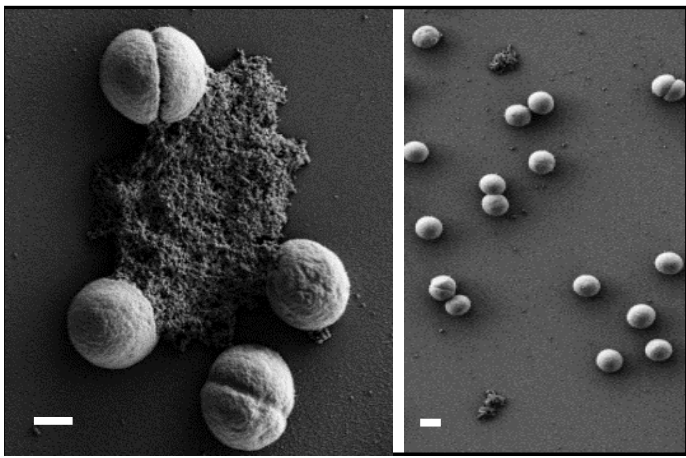

$\mathrm{BicA}^{+}$

(T485G)

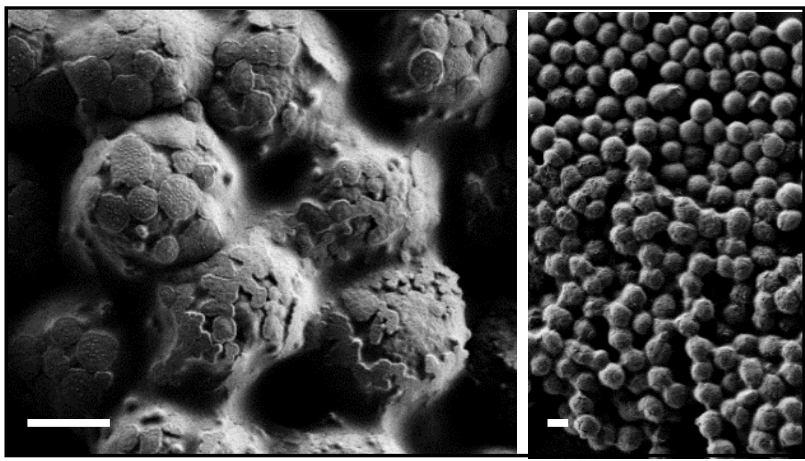


368 Figure 5. Ultrastructural analysis of $S .6803$ WT and engineered cells. Scanning

369 electromicrographs of $S .6803 \mathrm{WT} \mathrm{BicA}^{+}$, and $\mathrm{BicA}^{+}{ }_{(\mathrm{T} 485 \mathrm{G})}$ cells not induced (upper panel) or

370 strongly induced (lower panel) for the BicA constructs and cultivated with $100 \mathrm{mM} \mathrm{CO}_{2}$ for $1 \mathrm{~h}$.

371 Note aggregation of $\mathrm{BicA}^{+}{ }_{(\mathrm{T} 485 \mathrm{G})}$ cells compared to $\mathrm{BicA}^{+}$. Scale bar $=1 \mu \mathrm{m}$.

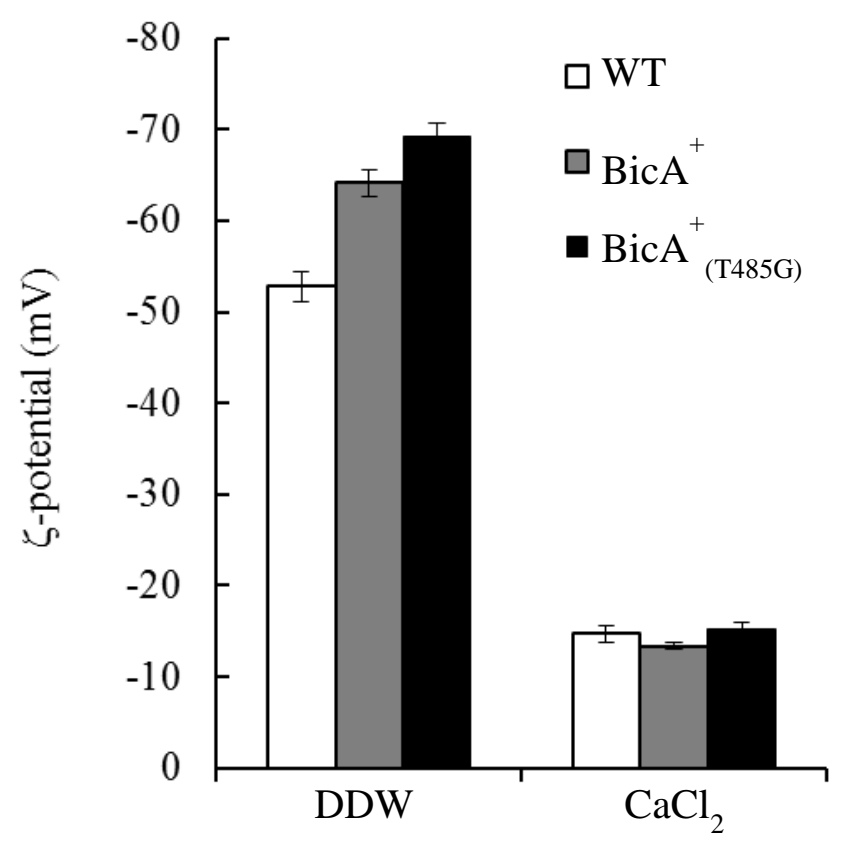

372 Figure 6. The $\zeta$-potential $(\mathrm{mV})$ measured as electrophoretic mobility for $S .6803 \mathrm{WT}, \mathrm{BicA}^{+}$, and

$373 \mathrm{BicA}_{(\mathrm{T} 485 \mathrm{G})}^{+}$cells strongly induced for the BicA constructs. The cells were gently harvested and

374 resuspended in either double distilled water (DDW) or $10 \mathrm{mM} \mathrm{CaCl}_{2}$ solution. Electrophoretic

375 mobility was determined for each of the treatments. Error bars represent standard deviation $376(n=5)$. 


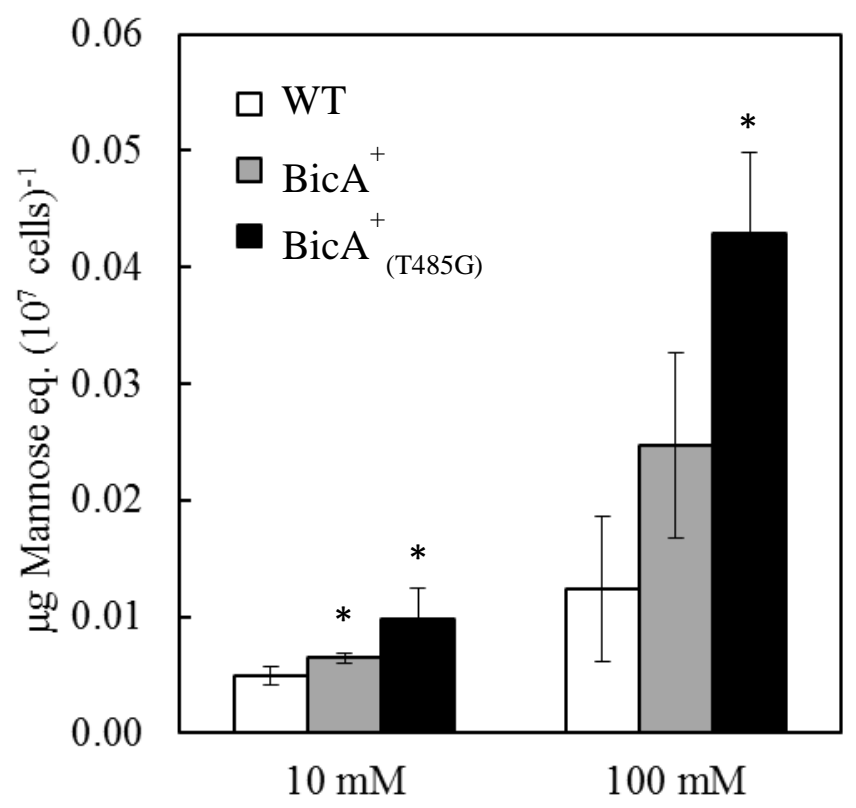

377

378

379

380

381

Figure 7. Quantification of extracellular carbohydrates. The amount of extracellular carbohydrates, expressed in $\mu \mathrm{m}$ mannose-equivalents $\left(10^{7} \text { cells }\right)^{-1}$, generated by strongly induced cells cultivated with $10 \mathrm{mM}$ or $100 \mathrm{mM} \mathrm{HCO}_{3}^{-}$for $1 \mathrm{~h}$.

* Denotes statistically significant difference as compared to the control (t-test, $\mathrm{p}<0.05)$.

\section{Quantification of extracellular carbohydrates}

Concentrations of extracellular saccharides exuded by $\mathrm{BicA}^{+}$and particularly by $\mathrm{BicA}^{+}{ }_{(\mathrm{T} 485 \mathrm{G})}$ cells incubated with $10 \mathrm{mM} \mathrm{HCO}_{3}^{-}$were significantly increased compared to the WT (t-test, $\mathrm{p}<0.05)$. When the $\mathrm{HCO}_{3}{ }^{-}$concentration shifted from 10 to $100 \mathrm{mM}$, accumulation of extracellular saccharides in the $\mathrm{BicA}^{+}{ }_{(\mathrm{T} 485 \mathrm{G})}$ strain became even more dramatic (Fig. 7).

\section{SR-FTIR metabolic fingerprinting}

As a direct assessment of the effect of $\mathrm{HCO}_{3}{ }^{-}$uptake on the metabolic features of the different strains, cells were incubated with $10 \mathrm{mM}$ or $100 \mathrm{mM} \mathrm{HCO}_{3}{ }^{-}$and assayed by synchrotronradiation Fourier transform infrared (SR-FTIR) phenotyping (Holman et al., 2010) (Supplemental Figure S4). The cluster vector plots of the biomolecular fingerprint region (1800$900 \mathrm{~cm}^{-1}$ ) of the SR-FTIR spectra revealed differences in the metabolic products of the strains, both in abundance and in composition relative to the WT (Fig. 8). When S. 6803 WT and the 
396

397

398

399

400

401

402

403

404

405

406

407

408

409

410

411

412

413

414

415

416

417

418

419

420

421

422

423

424

425

strongly induced $\mathrm{BicA}^{+}$and $\mathrm{BicA}_{(\mathrm{T} 485 \mathrm{G})}^{+}$strains were incubated with $10 \mathrm{mM}$ or $100 \mathrm{mM} \mathrm{HCO}_{3}{ }^{-}$, the $\mathrm{BicA}^{+}{ }_{(\mathrm{T} 485 \mathrm{G})}$ cells (Fig. 8, red traces) increased production of EPS rich in carbohydrates containing units of galactose, glucose, mannose, xylose (Fig. 8; diagnostic features in the 1200$900 \mathrm{~cm}^{-1}$ spectral region marked yellow), which possess the functional groups characterized by the $\mathrm{C}=\mathrm{O}$ bands of carboxylated anions near 1630 to $1600 \mathrm{~cm}^{-1}$; the $\mathrm{C}-\mathrm{H}$ of alkyl and alicyclic carboxylate groups near 1460 to $1400 \mathrm{~cm}^{-1}$, and sulfonyl functional groups $\mathrm{RS}(=\mathrm{O})_{2} \mathrm{R}^{\prime}$ near 1370 to $1305 \mathrm{~cm}^{-1}$ (Fig. 8, diagnostics indicated by black arrows) (Tipson, 1968; Kačuráková et al., 2000). For BicA ${ }^{+}$cells supplemented with $10 \mathrm{mM} \mathrm{HCO}_{3}{ }^{-}$, the increase in EPS productions was less pronounced than for $\mathrm{BicA}^{+}{ }_{(\mathrm{T} 485 \mathrm{G})}$ but became more evident with $100 \mathrm{mM} \mathrm{HCO}_{3}{ }^{-}$(Fig. 8, green trace). Compared with $\mathrm{BicA}^{+}{ }_{(\mathrm{T} 485 \mathrm{G})}$ and the WT strain, the EPS of $\mathrm{BicA}^{+}$at $100 \mathrm{mM}$ $\mathrm{HCO}_{3}{ }^{-}$was enriched with glycopyranose and aldopyranose derivatives (near $960 \mathrm{~cm}^{-1}$ ), propionic and higher ester $(\mathrm{C}-\mathrm{O})$ moieties $\left(1200-1170 \mathrm{~cm}^{-1}\right)$, benzoic and fatty acid $(\mathrm{C}-\mathrm{O})$ moieties $(1150$ $\left.1100 \mathrm{~cm}^{-1}\right)$, phosphate $\left(\mathrm{P}=\mathrm{O}\right.$ and $\left.\mathrm{PO}_{2}^{-}\right)$moieties $\left(1275-1200 \mathrm{~cm}^{-1}\right)$, and proteinaceous components (Fig. 8, diagnostic features in areas marked purple).

Figure 8. Metabolic phenotyping by SR-FTIR, a pair-wise analysis. Cluster vector plots of FTIR spectra in the biomolecular fingerprint region $\left(1800-900 \mathrm{~cm}^{-1}\right)$ for $\mathrm{BicA}^{+}$versus $S .6803 \mathrm{WT}$ (green trace), or $\mathrm{BicA}^{+}{ }_{(\mathrm{T} 485 \mathrm{G})}$ versus $S .6803 \mathrm{WT}$ (red trace). As a direct assessment of the effect of $\mathrm{HCO}_{3}{ }^{-}$uptake, cells were incubated with $10 \mathrm{mM}$ or $100 \mathrm{mM} \mathrm{HCO}_{3}{ }^{-}$. Features in the $1200-900$ $\mathrm{cm}^{-1}$ region arise mainly from the vibrational modes of different functional moieties of the EPS (yellow background). The $1690-1520 \mathrm{~cm}^{-1}$ region, represent mainly the vibrational modes of the amide I and II groups of the peptide component (purple background). Diagnostic peaks indicated by black arrows (see text). The more complicated feature (both positive and negative intensities) in the protein amide I region (1610-1690 $\mathrm{cm}^{-1}$ ) reflects a shifting in the population of the protein secondary structure and a change of the overall state of order of the proteins.

\section{DISCUSSION}

Growth dynamics and biomass accumulation measured for $S .6803$ (Fig. 2) demonstrate that, under our experimental conditions, cells were $C_{i}$ limited when purged with air containing atmospheric level of $\mathrm{CO}_{2}$. The WT strain accumulated higher biomass and grew almost twice as 
fast in cultures enriched with $0.5 \% \mathrm{CO}_{2}$ as compared to air. A similar stimulation in growth rate and biomass accumulation was obtained for air cultures by endowing cells with extra copies of the $\mathrm{HCO}_{3}{ }^{-}$transporter $\mathrm{BicA}$ (strain $\mathrm{BicA}^{+}$). Even with extra BicA transporters, however, airgrown $S .6803$ was somewhat $\mathrm{C}_{\mathrm{i}}$ limited, as growth rate and particularly biomass production of the $\mathrm{BicA}^{+}$strain further increased when cultivated with $0.5 \% \mathrm{CO}_{2}$ as compared to air, possibly demonstrating the low-affinity nature of BicA. There was no obvious difference in growth rate between strains in static non-aerated cultures, which, again, may reflect the low affinity of the BicA transporter. Increasing the $\mathrm{CO}_{2}$ concentration to $5 \%$ reduced the growth rate for WT and $\mathrm{BicA}^{+}$strain compared to $0.5 \% \quad \mathrm{CO}_{2}$ (Fig. 2A). Although cyanobacteria are commonly considered to be tolerant to high $p \mathrm{CO}_{2}$, the response to increased $\mathrm{CO}_{2}$ levels differs widely between cyanobacterial species (Miyachi et al., 2003), and S. 6803 has been shown to exhibit only moderate tolerance to high $\mathrm{CO}_{2}$ concentrations (Thomas et al., 2005). The reason(s) for high- $\mathrm{CO}_{2}$ toxicity in many autotrophs, including plants, algae, and cyanobacteria, is not fully understood but is likely to be due to the impairment of the rubisco enzyme and the CalvinBenson cycle by the acidic conditions generated by high $\mathrm{CO}_{2}$ concentrations (Miyachi et al., 2003).

As opposed to the $\mathrm{BicA}^{+}$strain, no increased growth rate over the WT was observed for the $\mathrm{BicA}_{(\mathrm{T} 485 \mathrm{G})}^{+}$strain in air cultures (although we may have underestimated growth of the $\mathrm{BicA}_{(\mathrm{T} 485 \mathrm{G})}^{+}$strain due to the flocculating nature of the culture). Reduced growth of BicA ${ }^{+}$with $5 \% \mathrm{CO}_{2}$ as compared to the WT suggests that the presence of extra BicA transporters was detrimental under conditions of high $\mathrm{C}_{\mathrm{i}}$ availability, and is in agreement with the notion that allosteric down-regulation of BicA does not obstruct its transport activity but rather decreases its affinity for the substrate ((Sültemeyer et al., 1998) and references therein). Failure of $\mathrm{BicA}_{(\mathrm{T} 485 \mathrm{G})}^{+}$cells to grow under $5 \% \mathrm{CO}_{2}$ demonstrates that the threonine-to-glycine mutation of T485 in the C-terminal STAS domain of BicA is lethal under high- $\mathrm{CO}_{2}$ conditions. Previous studies suggested that the C-terminal cytoplasmic STAS domain is involved in protein-protein interaction and contains a putative phosphorylation site (Shelden et al., 2010; Price, 2011). The potentially phosphorylatable threonine (T485) in BicA of S. 6803 is homologous to serine (S58) in SpoIIAA of Bacillus subtilis (Aravind and Koonin, 2000), with the serine shown to undergo phosphorylation (Macek et al., 2007) and to play a crucial role in activity regulation of the antisigma factor SpoIIAA (Diederich et al., 1994). Additionally, fast decay of $\mathrm{HCO}_{3}{ }^{-}$uptake in $S$. 
6803 shifted to high $\mathrm{CO}_{2}$ conditions is accompanied by in vivo protein phosphorylation, suggesting specific inactivation of $\mathrm{HCO}_{3}{ }^{-}$transport activity and identifying phosphorylation as the regulatory switch of $p \mathrm{CO}_{2}$-responsive $\mathrm{HCO}_{3}{ }^{-}$transport systems (Bloye et al., 1992). Altogether, previous knowledge suggests that STAS domain is involved in allosteric control of the BicA activity; under increased DIC levels it undergoes regulatory phosphorylation that suppresses $\mathrm{HCO}_{3}{ }^{-}$influx activity of BicA. Therefore, alteration of the regulatory phosphorylation switch in BicA disabled downregulation of its activity and the overexpressed $\mathrm{Bic}_{(\mathrm{T} 485 \mathrm{G})}$ transporter presumably maintained high $\mathrm{HCO}_{3}{ }^{-}$influx even under elevated $p \mathrm{CO}_{2}$, causing the lethal phenotype of $\mathrm{BicA}^{+}{ }_{(\mathrm{T} 485 \mathrm{G})}$. As excess $\mathrm{C}_{\mathrm{i}}$ can "leak" from a cell, we speculate that the lethal phenotype of $\mathrm{BicA}_{(\mathrm{T} 485)}^{+}$was caused by excessive cellular uptake of $\mathrm{Na}^{+}$rather than $\mathrm{HCO}_{3}{ }^{-}$. Activity of the $\mathrm{HCO}_{3}{ }^{-} \mathrm{Na}^{+}$symport, that is non-responsive to regulative feedback, dramatically increases intracellular $\mathrm{Na}^{+}$concentration and may trigger a surge of $\mathrm{H}^{+}$influx through $\mathrm{Na}^{+} / \mathrm{H}^{+}$ antiports. Genome annotation suggests the presence of five $\mathrm{Na}^{+} / \mathrm{H}^{+}$antiports in $S .6803$ cells (Waditee et al., 2006), and $\mathrm{Na}^{+} / \mathrm{H}^{+}$antiports are likely to be ancillary components of cyanobacterial CCMs and important for maintaining $\mathrm{Na}^{+}$homeostasis (Fig. 1) (Waditee et al., 2006; Price, 2011). Superior performance of $\mathrm{BicA}^{+}$over $\mathrm{BicA}_{(\mathrm{T} 485 \mathrm{G})}^{+}$in air-infused cultures further implies that STAS domain-controlled regulation, in addition to being a $p \mathrm{CO}_{2}$ gauge, may be responsive for intracellular $\mathrm{Na}^{+}$and/or $\mathrm{pH}$ homeostasis. Further studies are required to elucidate the mechanism underlying failure of $\mathrm{BicA}^{+}{ }_{(\mathrm{T} 485 \mathrm{G})}$ to grow under $5 \% \mathrm{CO}_{2}$ particularly and the detrimental effect of unregulated BicA activity in general.

When maximal rates of $\mathrm{HCO}_{3}{ }^{-}$consumption were assessed through the rate of $\mathrm{O}_{2}$ evolution (Fig. 3), comparable values were measured for all strains when supplemented with $<100 \mu \mathrm{M} \mathrm{HCO}_{3}{ }^{-}$. A considerably higher capacity for $\mathrm{HCO}_{3}{ }^{-}$utilization was recorded for the strongly induced $\mathrm{BicA}^{+}$and $\mathrm{BicA}_{(}^{+}{ }_{(485 \mathrm{G})}$ cells compared to the WT, when $\mathrm{HCO}_{3}{ }^{-}$concentrations were above the $100 \mu \mathrm{M}$ threshold. These findings likely reflect the properties of the BicA transporter; under low to moderate $\mathrm{HCO}_{3}{ }^{-}$levels, the low-affinity activity of BicA is overshadowed by the activity of the high-affinity $\mathrm{HCO}_{3}{ }^{-}$transporters strongly induced under those conditions in all strains (BicA photosynthetic affinity $\mathrm{K}_{0.5}\left(\mathrm{HCO}_{3}{ }^{-}\right)=171 \pm 15 \mu \mathrm{M}$ (Price et al., 2004) as compared to $\leq 15 \mu \mathrm{M}$ for higher affinity $\mathrm{C}_{\mathrm{i}}$ transporters (Price and Howitt, 2010)), and under elevated $\mathrm{HCO}_{3}{ }^{-}$ concentrations $(>100 \mu \mathrm{M})$, the high-flux nature of the overexpressed BicA is manifested as a surplus photosynthetic $\mathrm{C}$ fixation. When the direct consumption of DIC from the growth medium 
was measured in cultures strongly induced for BicA constructs (Fig. 4), $\mathrm{BicA}^{+}{ }_{(\mathrm{T} 485 \mathrm{G})}$ demonstrated a statistically significant increase in DIC uptake rate compared to the WT, while the uptake for $\mathrm{BicA}^{+}$was similar to the highly variable WT activity. We ascribe the high variability in DIC acquisition between biological replicates for the WT to stress caused the by acute exposure to $\mathrm{HCO}_{3}{ }^{-}\left(100 \mathrm{mM} \mathrm{HCO}_{3}{ }^{-}\right.$is $>500$ times the $\mathrm{C}$ concentration in standard $\left.\mathrm{BG} 11\right)$ and potentially exaggerated by the effect of $\mathrm{N}$ starvation. This variable response of the WT strain is akin to the generally unstable growth in $\mathrm{BicA}^{+}{ }_{\text {(T485G) }}$ cultures (Supplemental Table SII), but here the exposure to excessive levels of $\mathrm{HCO}_{3}{ }^{-}$is likely caused by unregulated uptake of $\mathrm{HCO}_{3}{ }^{-}$ by the $\mathrm{Bic}_{(\mathrm{T} 485 \mathrm{G})}$ transporter. To the contrary, low variability in DIC acquisition between the $\mathrm{BicA}^{+}$replicates implies metabolic preconditioning of $\mathrm{Bic}^{+}$cells to increased $\mathrm{C}_{\mathrm{i}}$ availability and demonstrates controlled DIC uptake at a rate above the WT average. Further studies including proteomic and metabolomic approaches are required to identify metabolic adjustments involved in the adaptation to increased C availability in $S .6803$.

Increased $\mathrm{C}_{\mathrm{i}}$ availability has been shown to trigger production of C-rich compounds such as glycogen (Stöckel et al., 2013) or EPS (De Philippis et al., 1996) in different strains of cyanobacteria. In agreement with their elevated photosynthetic $\mathrm{HCO}_{3}{ }^{-}$fixation, strongly induced $\mathrm{BicA}^{+}$and $\mathrm{BicA}_{(\mathrm{T} 485 \mathrm{G})}^{+}$cells supplemented with increased levels of DIC increased the accumulation of extracellular saccharides compared to the WT (Fig. 7). The extensive release of assimilated excess $\mathrm{C}$ to the external medium, which was particularly evident at the highest DIC levels (Fig. 7), is indicative of an "overflow metabolism" that has been well established in cyanobacteria under conditions of C surplus (De Philippis et al., 1996; Gordillo et al., 1998; Otero and Vincenzini, 2004; Cook et al., 2007).

Ultrastructural SEM and lectin stains analyses of induced $\mathrm{BicA}^{+}{ }_{(\mathrm{T} 485 \mathrm{G})}$ cells confirmed the presence of copious EPS, which potentially contributed to formation of cell clumps in the culture (Fig. 2D, 5, and S5). For induced $\mathrm{BicA}^{+}$and $\mathrm{BicA}_{(\mathrm{T} 485 \mathrm{G})}^{+}$, the increase in negative $\zeta$-potential that could be neutralized by $\mathrm{Ca}^{2+}$ in a solute (Fig. 6) indicates that accumulation of negativelycharged EPS on the exterior cell surface was higher than for WT cells. The lack of aggregate formation in EPS-associated $\mathrm{BicA}^{+}$cells (Fig. 5) may be indicative of differences in physicochemical properties of generated EPS compounds between $\mathrm{BicA}^{+}$and $\mathrm{BicA}^{+}{ }_{(\mathrm{T} 485 \mathrm{G})}$ cells. Based on molecular analysis of the FTIR cells spectra, we conclude with a $95 \%$ confidence (supplemental Fig. S6) that the EPS composition for $\mathrm{BicA}^{+}$and $\mathrm{BicA}_{(\mathrm{T} 485 \mathrm{G})}^{+}$strains differed 
substantially; EPS formed by $\mathrm{BicA}^{+}{ }_{(\mathrm{T} 485 \mathrm{G})}$ was more polyanionic in nature, with higher content of negatively charged residues, e.g., alkyl and alicylic carboxylates and carboxylic acids, whereas a distinguishing feature of EPS in $\mathrm{BicA}^{+}$cells was an abundance of phosphate moieties and inclusion of proteinaceous structures (Fig. 8). The more negative charge in $\mathrm{BicA}_{(\mathrm{T} 485 \mathrm{G})}^{+}$EPS could conceivably enhance electrostatic interactions between EPS-associated particles and contribute to cell flocculation.

\section{CONCLUSIONS}

We show that the presence of extra BicA transporters in the $S .6803 \mathrm{BicA}^{+}$and $\mathrm{BicA}^{+}{ }_{(\mathrm{T} 485 \mathrm{G})}$ strains increased the capacity for $\mathrm{HCO}_{3}{ }^{-}$uptake. When cultured under atmospheric $p \mathrm{CO}_{2}$, the $\mathrm{BicA}^{+}$strain grew almost twice as fast as the control, and produced substantially more biomass. The $\mathrm{BicA}^{+}$strain produced more biomass than the WT also at $0.5 \%$ and $5 \% \mathrm{CO}_{2}$ enrichment, although its growth rate deduced from the culture turbidity (Fig. S4) was comparable to that of the WT strain. The excess fixed $\mathrm{C}$ that was not assimilated into cellular biomass by the Bic ${ }^{+}$ and $\mathrm{BicA}^{+}{ }_{(\mathrm{T} 485 \mathrm{G})}$ strains was funneled to the production of EPS. Phenotypic characterization of the $\mathrm{BicA}^{+}{ }_{(\mathrm{T} 485 \mathrm{G})}$ strain was consistent with T485 in BicA's cytosolic STAS domain being involved in reversible phosphorylation as part of a feedback regulation of $\mathrm{HCO}_{3}{ }^{-}$transport activity by altering BicA's substrate affinity. The decreased overall fitness of the $\mathrm{BicA}^{+}{ }_{(\mathrm{T} 485 \mathrm{G})}$ strain as compared to $\mathrm{BicA}^{+}$, demonstrates the importance of the endogenous control system that has evolved to fine-tune the CCM in cyanobacteria. Augmentation of physiological capacity of a cell through multiplication of its endogenous molecular components is a novel approach that enhances a desired trait of a harmonized metabolic system building upon its inherited resilience yet in a targeted manner. We advocate wider adoption of this approach in toolkit of metabolic engineering. Finally, we propose that the $\mathrm{BicA}^{+}$strain, which exhibited increase in the photosynthetic source strength (the "push" end of photosynthesis), provides an ideal platform for engineering of the photosynthesis "pull" end to redirect the excess photosynthate from EPS to Crich end products, e.g., photosynthetic fuel and chemicals.

\section{ACKNOWLEDGMENTS}

We are grateful to Prof. Krishna K. Nyogi and his lab members for use of their oxygen electrode. 
548 This work was supported in part by the U.S. Department of Energy Contract DEAC02-

549 05CH11231 with Lawrence Berkeley National Laboratory. Use of the facilities at the LBNL

550 Molecular Foundry was supported by Molecular Foundry Project \#1794. The SR-FTIR and

551 associated imaging work were performed at Infrared Beamline 1.4 and 5.4 under the Berkeley

552 Synchrotron Infrared Structural Biology (BSISB) Program funded by the U.S. Department of

553 Energy, Office of Science and Office of Biological and Environmental Research through

554 contracts DEAC02-05CH11231. The Advanced Light Source is supported by the Director,

555 Office of Science, Office of Basic Energy Sciences, of the U.S. Department of Energy under

556 Contract No. DE-AC02-05CH11231.

557

558

559

560

561

562

563

564

565

566

567

568

569

570

571

572 


\section{REFERENCES}

Aravind L, Koonin EV (2000) The STAS domain - a link between anion transporters and antisigma-factor antagonists. Current Biology 10: R53-R55

Bennett A, Bogorad L (1973) Complementary chromatic adaptation in a filamentous blue-green alga. The Journal of Cell Biology 58: 419-435

Bloye SA, Silman NJ, Mann NH, Carr NG (1992) Bicarbonate concentration by Synechocystis PCC6803 : Modulation of protein phosphorylation and inorganic carbon transport by glucose. Plant Physiology 99: 601-606

Brandenburg K, Seydel U (1996) Fourier transform infrared spectroscopy of cell surface polysaccharides. In HH Mantsch, D Chapman, eds, Infrared Spectroscopy of Biomolecules. Wiley-Liss, New York, pp 203-238

Cabaniss SE, McVey IF (1995) Aqueous infrared carboxylate absorbances: aliphatic monocarboxylates. Spectrochimica Acta Part A: Molecular and Biomolecular Spectroscopy 51: 2385-2395

Cannon GC, Heinhorst S, Kerfeld CA (2010) Carboxysomal carbonic anhydrases: Structure and role in microbial $\mathrm{CO}_{2}$ fixation. Biochimica et Biophysica Acta (BBA) - Proteins and Proteomics 1804: 382-392

Cook PLM, Veuger B, Böer S, Middelburg JJ (2007) Effect of nutrient availability on carbon and nitrogen incorporation and flows through benthic algae and bacteria in near-shore sandy sediment. Aquatic Microbial Ecology 49: 165-180

Dai G-Z, Qiu B-S, Forchhammer K (2014) Ammonium tolerance in the cyanobacterium Synechocystis sp. strain PCC 6803 and the role of the psbA multigene family. Plant, Cell \& Environment 37: 840-851

Daley SME, Kappell AD, Carrick MJ, Burnap RL (2012) Regulation of the cyanobacterial $\mathrm{CO}_{2}$-concentrating mechanism involves internal sensing of $\mathrm{NADP}^{+}$and $\alpha$-ketogutarate levels by transcription factor CcmR. PLOS one 7: e41286

De Philippis R, Sili C, Vincenzini M (1996) Response of an exopolysaccharide-producing heterocystous cyanobacterium to changes in metabolic carbon flux. Journal of Applied Phycology 8: 275-281 
Diederich B, Wilkinson JF, Magnin T, Najafi SMA, Errington J, Yudkin MD (1994) Role of interactions between SpoIIAA and SpoIIAB in regulating cell-specific transcription factor $\sigma^{\mathrm{F}}$ of Bacillus subtilis. Genes and Development 8: 2653-2663

Ducat DC, Avelar-Rivas JA, Way JC, Silver PA (2012) Rerouting carbon flux to enhance photosynthetic productivity. Applied and Environmental Microbiology 78: 2660-2668 Eaton-Rye JJ (2010) Construction of gene interruptions and gene deletions in the cyanobacterium Synechocystis sp. strain PCC 6803. In R Carpentier, ed, Photosynthesis Research Protocols, Vol 684. Human Press, Totowa, NJ, pp 295-312

Eisenhut M, Ruth W, Haimovich M, Bauwe H, Kaplan A, Hagemann M (2008) The photorespiratory glycolate metabolism is essential for cyanobacteria and might have been conveyed endosymbiontically to plants. Proceedings of the National Academy of Sciences 105: 17199-17204

Friederich GE, Walz PM, Burczynski MG, Chavez FP (2002) Inorganic carbon in the central California upwelling system during the 1997-1999 El Niño-La Niña event. Progress in Oceanography 54: 185-203

Giordano M, Beardall J, Raven JA (2005) $\mathrm{CO}_{2}$ concentrating mechanisms in algae: Mechanisms, environmental modulation, and evolution. In Annual Review of Plant Biology, Vol 56. Annual Reviews, Palo Alto, pp 99-131

Gordillo F, Jiménez C, Figueroa F, Niell F (1998) Effects of increased atmospheric $\mathrm{CO}_{2}$ and N supply on photosynthesis, growth and cell composition of the cyanobacterium Spirulina platensis (Arthrospira). Journal of Applied Phycology 10: 461-469

Holman H-YN, Bechtel HA, Hao Z, Martin MC (2010) Synchrotron IR spectromicroscopy: Chemistry of living cells. Analytical Chemistry 82: 8757-8765

Hu P, Borglin S, Kamennaya NA, Chen L, Park H, Mahoney L, Kijac A, Shan G, Chavarría KL, Zhang C, Quinn NWT, Wemmer D, Holman H-Y, Jansson C (2013)

Metabolic phenotyping of the cyanobacterium Synechocystis PCC 6803 engineered for production of alkanes and free fatty acids. Applied Energy 102: 850-859

Iwaki T, Haranoh K, Inoue N, Kojima K, Satoh R, Nishino T, Wada S, Ihara H, Tsuyama S, Kobayashi H, Wadano A (2006) Expression of foreign type I ribulose-1,5-bisphosphate carboxylase/oxygenase (EC 4.1.1.39) stimulates photosynthesis in cyanobacterium Synechococcus PCC7942 cells. Photosynthesis Research 88: 287-297 
Jansson C (2005) Mutation: Sugar signaling mutants in Arabidopsis. In K Esser, U Lüttge, W Beyschlag, J Murata, eds, Progress in Botany, Vol 66. Springer Berlin Heidelberg, pp 50-67 Jansson C, Debus R, Osiewacz H, Gurevitz M, Mcintosh L (1987) Invitro mutagenesis of psbA genes in Synechocystis 6803. Journal of Cellular Biochemistry: 14-14

Jansson C, Debus RJ, Osiewacz HD, Gurevitz M, Mcintosh L (1987) Construction of an obligate photoheterotrophic mutant of the cyanobacterium Synechocystis 6803 - inactivation of the $p s b A$ gene family. Plant Physiology 85: 1021-1025

Jansson C, Wullschleger SD, Udaya CK, Tuskan GA (2010) Phytosequestration: Carbon biosequestration by plants and the prospects of genetic engineering. BioScience 60: 685-696 Kačuráková M, Capek P, Sasinková V, Wellner N, Ebringerová A (2000) FT-IR study of plant cell wall model compounds: pectic polysaccharides and hemicelluloses. Carbohydrate Polymers 43: 195-203

Kaplan A, Badger MR, Berry JA (1980) Photosynthesis and the intracellular inorganic carbon pool in the bluegreen alga Anabaena variabilis: Response to external $\mathrm{CO}_{2}$ concentration. Planta 149: $219-226$

Karagouni AD, Bloye SA, Carr NG (1990) The presence and absence of inorganic carbon concentrating systems in unicellular cyanobacteria. FEMS Microbiology Letters 68: 137-141 Lichtentahler HK (1987) Chlorophylls and carotenoids: Pigments of photosynthetic biomembranes. Methods in Enzymology 148: 350-382

Long BM, Tucker L, Badger MR, Price GD (2010) Functional cyanobacterial betacarboxysomes have an absolute requirement for both long and short forms of the CcmM protein. Plant Physiology 153: 285-293

Macek B, Mijakovic I, Olsen JV, Gnad F, Kumar C, Jensen PR, Mann M (2007) The serine/threonine/tyrosine phosphoproteome of the model bacterium Bacillus subtilis. Molecular \& Cellular Proteomics 6: 697-707

Masuko T, Minami A, Iwasaki N, Majima T, Nishimura S-I, Lee YC (2005) Carbohydrate analysis by a phenol-sulfuric acid method in microplate format. Analytical Biochemistry 339: $69-72$

McCormick AJ, Crame MD, Watt DA (2006) Sink-strength regulates photosynthesis in sugarcane. South African Journal of Botany 72: 325-325 
Miyachi S, Iwasaki I, Shiraiwa Y (2003) Historical perspective on microalgal and cyanobacterial acclimation to low- and extremely high- $\mathrm{CO}_{2}$ conditions. Photosynthesis Research 77: $139-153$

Naumann D (2000) Infrared Spectroscopy in Microbiology. In RA Meyers, ed, Encyclopedia of Analytical Chemistry. John Wiley \& Sons Ltd, Chichester, pp 102-131

Neu TR, Lawrence JR (1997) Development and structure of microbial biofilms in river water studied by confocal laser scanning microscopy. Fems Microbiology Ecology 24: 11-25 Oliver JWK, Machado IMP, Yoneda H, Atsumi S (2013) Cyanobacterial conversion of carbon dioxide to 2,3-butanediol. Abstracts of Papers of the American Chemical Society 246 Otero A, Vincenzini M (2004) Nostoc (Cyanophyceae) goes nude: extracellular polysaccharides serve as a sink for reducing power under unbalanced C/N metabolism. Journal of Phycology 40: $74-81$

Paul M, Pellny T, Goddijn O (2001) Enhancing photosynthesis with sugar signals. Trends in Plant Science 6: 197-200

Price GD (2011) Inorganic carbon transporters of the cyanobacterial $\mathrm{CO}_{2}$ concentrating mechanism. Photosynthesis Research 109: 47-57

Price GD, Howitt SM (2010) The cyanobacterial bicarbonate transporter BicA: its physiological role and the implications of structural similarities with human SLC26 transporters. Biochemistry and Cell Biology 89: 178-188

Price GD, Woodger FJ, Badger MR, Howitt SM, Tucker L (2004) Identification of a SulPtype bicarbonate transporter in marine cyanobacteria. Proceedings of the National Academy of Sciences 101: 18228-18233

Qi Q, Hao M, Ng W-o, Slater SC, Baszis SR, Weiss JD, Valentin HE (2005) Application of the Synechococcus nirA promoter to establish an inducible expression system for engineering the Synechocystis tocopherol pathway. Applied and Environmental Microbiology 71: 5678-5684 Rae BD, Long BM, Badger MR, Price GD (2013) Functions, compositions, and evolution of the two types of carboxysomes: Polyhedral microcompartments that facilitate $\mathrm{CO}_{2}$ fixation in cyanobacteria and some proteobacteria. Microbiology and Molecular Biology Reviews 77: 357379 
Ramanan R, Vinayagamoorthy N, Sivanesan SD, Kannan K, Chakrabarti T (2012)

Influence of $\mathrm{CO}_{2}$ concentration on carbon concentrating mechanisms in cyanobacteria and green algae: A proteomic approach. Algae 27: 295-301

Raven JA, Cockell CS, De La Rocha CL (2008) The evolution of inorganic carbon concentrating mechanisms in photosynthesis. Philosophical Transactions of the Royal Society B: Biological Sciences 363: 2641-2650

Reece KS, Phillips GJ (1995) New plasmids carrying antibiotic-resistance cassettes. Gene 165: $141-142$

Rolland F, Baena-Gonzalez E, Sheen J (2006) Sugar sensing and signaling in plants:

Conserved and novel mechanisms. Annual Review of Plant Biology 57: 675-709

Salon C, Mir NA, Canvin DT (1996) $\mathrm{HCO}_{3}{ }^{-}$and $\mathrm{CO}_{2}$ leakage from Synechococcus UTEX 625. Plant, Cell \& Environment 19: 260-274

Sengbusch Pv, Müller U (1983) Distribution of glycoconjugates at algal cell surfaces as monitored by FITC-conjugated lectins. Studies on selected species from Cyanophyta, Pyrrhophyta, Raphidophyta, Euglenophyta, Chromophyta , and Chlorophyta. Protoplasma 114: 103-113

Shelden MC, Howitt SM, Price GD (2010) Membrane topology of the cyanobacterial bicarbonate transporter, BicA, a member of the SulP (SLC26A) family. Molecular Membrane Biology 27: 11-22

Sicora CI, Ho FM, Salminen T, Styring S, Aro E-M (2009) Transcription of a "silent" cyanobacterial $p s b A$ gene is induced by microaerobic conditions. Biochimica et Biophysica Acta (BBA) - Bioenergetics 1787: 105-112

Stanier RY, Kunisawa R, Mandel M, Cohen-Bazire G (1971) Purification and properties of unicellular blue-green algae (order Chroococcales). Bacteriological Reviews 35: 171-205

Stöckel J, Elvitigala TR, Liberton M, Pakrasi HB (2013) Carbon availability affects diurnally controlled processes and cell morphology of Cyanothece 51142. PLOS one 8: e56887

Sültemeyer D, Klughammer B, Badger MR, Price GD (1998) Protein phosphorylation and its possible involvement in the induction of the high-affinity $\mathrm{CO}_{2}$ concentrating mechanism in cyanobacteria. Canadian Journal of Botany-Revue Canadienne De Botanique 76: 954-961 
Suzuki I, Sugiyama T, Omata T (1993) Primary structure and transcriptional regulation of the gene for nitrite reductase from the cyanobacterium Synechococcus PCC 7942. Plant and Cell Physiology 34: 1311-1320

Thomas DJ, Sullivan SL, Price AL, Zimmerman SM (2005) Common freshwater cyanobacteria grow in $100 \% \mathrm{CO}_{2}$. Astrobiology 5: 66-74

Tipson RS (1968) Infrared Spectroscopy of Carbohydrates: A Review of the Literature., Vol 110. U.S. Government Printing Office, Washington D.C.

Waditee R, Tanaka Y, Takabe T (2006) $\mathrm{Na}+/ \mathrm{H}+$ antiporters in plants and cyanobacteria. In A Rai, T Takabe, eds, Abiotic stress tolerance in plants. Springer Netherlands, pp 163-175 Wang H-L, Postier BL, Burnap RL (2004) Alterations in global patterns of gene expression in Synechocystis sp. PCC 6803 in response to inorganic carbon limitation and the inactivation of $n d h R$, a LysR family regulator. Journal of Biological Chemistry 279: 5739-5751 Yeates TO, Crowley CS, Tanaka S (2010) Bacterial microcompartment organelles: Protein shell structure and evolution. Annual Review of Biophysics 39: 185-205 
$10 \mathrm{mM} \mathrm{HCO}{ }^{-}$

$\mathrm{BicA}^{+}$vs WT
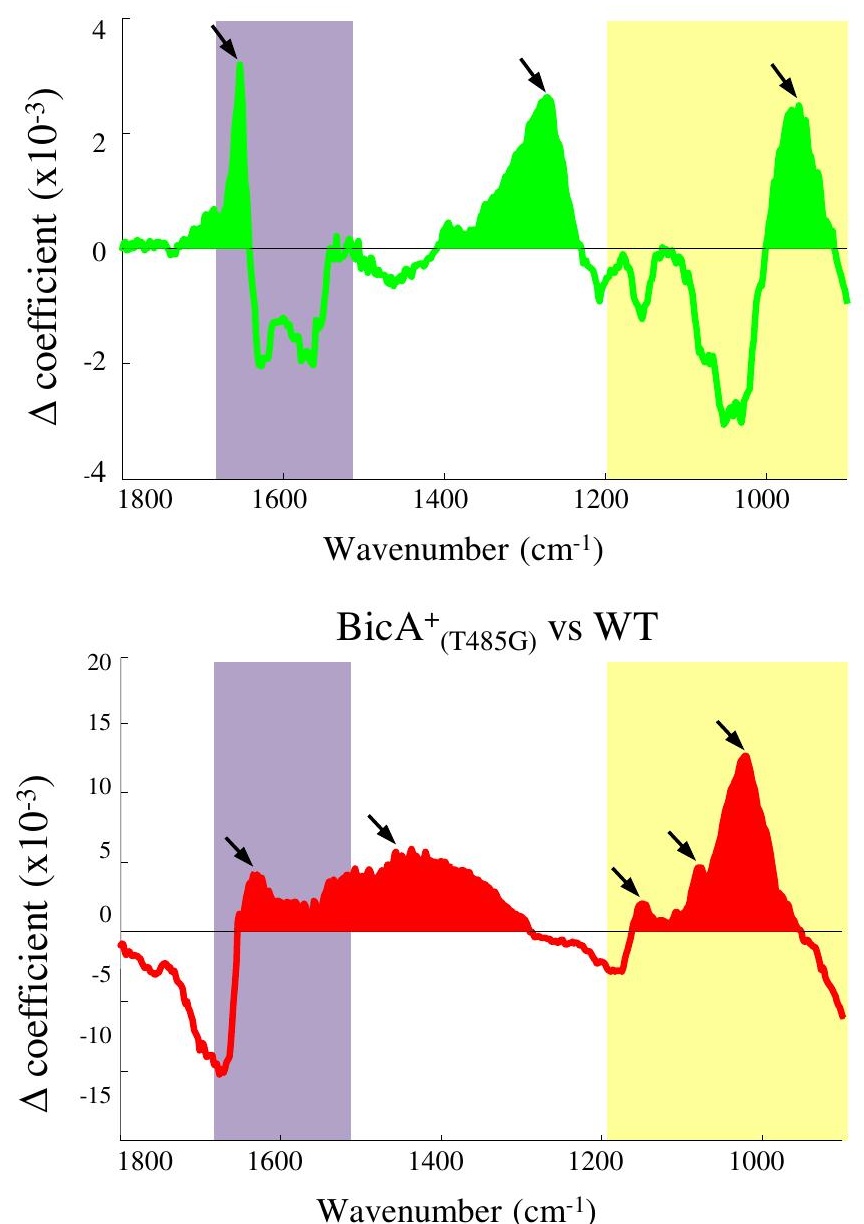

$100 \mathrm{mM} \mathrm{HCO}_{3}^{-}$

$\mathrm{BicA}^{+}$vs WT
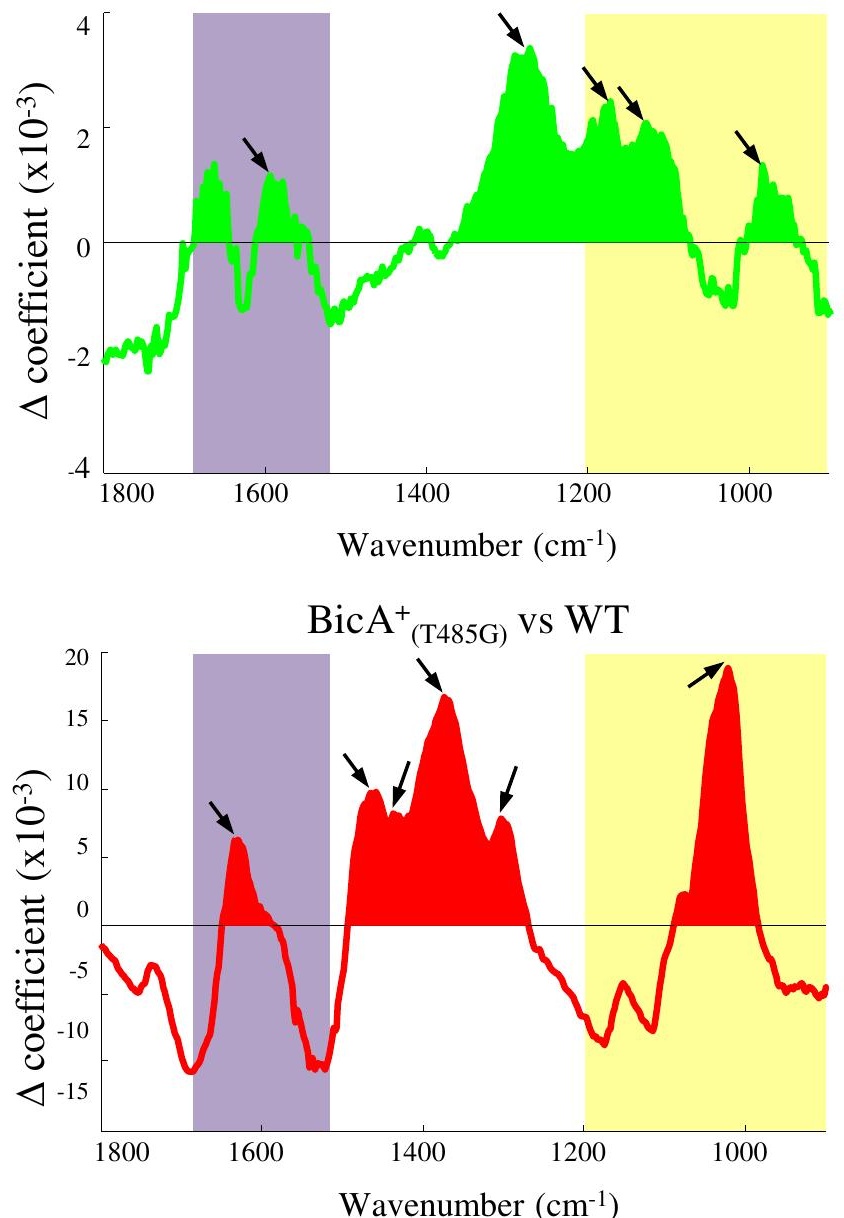